\title{
Explorando a Ambidestria Organizacional e Design Thinking na Análise de Processos de Negócio
}

\author{
Higor R. Monteiro Santos ${ }^{1,2}$ e Carina Frota Alves ${ }^{1}$ \\ ${ }^{1}$ Centro de Informática - Universidade Federal de Pernambuco (CIn - UFPE) \\ ${ }^{2}$ Universidade de Pernambuco (UPE) \\ hrms, cfa@cin.ufpe.br
}

\begin{abstract}
There is a growing concern of organizations to continually improve their processes and adapt them to the customer expectations, needs and experience. However, despite the Business Process Management to be effective in analyzing and improving processes, researchers suggest that it is not sufficiently provided with capabilities and techniques to explore outside-in opportunities. Design Thinking and Organizational Ambidexterity are approaches that allow a balance between improving internal efficiency, as well as the analysis of the external environment in search of innovation. In this context, the main research objective is to investigate how the business process analysis can be performed to achieve incremental improvement and exploration of future opportunities. As a result, we developed a method that systematizes the analysis processes phase through methodological framework Design Science Research. Furthermore, an evaluation of the method was performed with experts and applied in an organization in order to verify the perceived utility and ease-of-use. As future work, it will be realized a quasiexperiment in a BPM initiative.
\end{abstract}

Resumo. Existe uma preocupação crescente nas organizações em melhorar seus processos continuamente e adequá-los às expectativas, necessidades e experiência dos clientes. No entanto, apesar da Gestão de Processos de Negócio ser eficiente na análise e melhoria incremental dos processos, pesquisadores afirmam que ela não está suficientemente provida de capacidades e técnicas para explorar oportunidades de fora para dentro. Design Thinking e Ambidestria Organizacional são abordagens que permitem o equilibrio entre a melhoria da eficiência interna, assim como a análise do ambiente externo em busca de inovações. Nesse contexto, o objetivo principal dessa pesquisa é investigar como a análise de processo de negócio pode ser realizada para alcançar a melhoria incremental $e$ a exploração de oportunidades futuras. Como resultado, foi elaborado um método que sistematiza a fase de análise de processos por meio do arcabouço metodológico Design Science Research. Além da proposição, o método foi avaliado por especialistas e aplicado numa organização a fim de verificar a utilidade, a facilidade de entendimento e aplicabilidade. Como trabalho futuro, será realizado um quasi-experimento numa iniciativa de Gestão de Processos de Negócios. 


\section{Introdução}

Os objetivos organizacionais são percebidos na execução das atividades que adicionam valor à própria instituição e aos seus clientes (Kotler e Armstrong, 2009). No contexto de organizações privadas, a geração de valor corresponde essencialmente ao lucro, aumento do mercado e consolidação da marca. Para organizações públicas ou não lucrativas, a prioridade é oferecer serviços de excelência aos cidadãos que consumam o mínimo de recursos. A busca constante por alcançar os objetivos estratégicos e maximizar o retorno sobre os investimentos reforçam a relevância de progressivamente melhorar os processos de negócio. Apesar de envolver diversos fatores críticos de sucesso, a introdução das práticas de Gestão de Processos de Negócio (BPM) tem sido uma alternativa bastante escolhida para alinhar áreas estratégicas e setores funcionais das organizações (Santos, Valença e Alves, 2015; Trkman, 2010).

No entanto, Rosemann (2014) afirma que BPM, como disciplina de gestão, parece não ser suficientemente provida para explorar o potencial de um ambiente cada vez mais rico em oportunidades. Uma das principais razões é que as metodologias e técnicas atuais de BPM normalmente seguem um paradigma 'inside-out', também chamado de pensamento analítico. Esse modelo aborda o gerenciamento através de exploitation techniques que se repetem continuamente ao longo do tempo (Martin, 2009). Tanto BPM quanto outras abordagens de gestão, tais como, Total Quality Management (TQM), Six-sigma e Lean, dispõem de consolidados conhecimentos, recursos e ferramentas para analisar e resolver problemas organizacionais "de dentro para fora".

Kohlborn et al. (2014) identificou que é necessário complementar a abordagem BPM com o paradigma outside-in ("de fora para dentro"), chamado também de pensamento intuitivo. Dessa forma, a relevância e o impacto das oportunidades externas ou que não são óbvias podem ser rapidamente avaliadas e implementadas. $\mathrm{O}$ pensamento intuitivo está centrado no pensamento divergente, na criatividade, originalidade e na invenção (Martin, 2009).

Organizações com capacidades para administrar os pensamentos analítico e intuitivo são denominadas de Organizações Ambidestras. Apesar desse conceito ter sido criado em 1976 por Duncan (1976) e as pesquisas nesse sentido terem evoluído bastante, ainda permanecem confusões sobre o que este conceito realmente significa (O'Reilly e Tushman, 2013). Ambidestria Organizacional não envolve simplesmente se uma empresa pode alcançar a eficiência e inovação ou competir em vários mercados. Esse conceito engloba o desenvolvimento das capacidades necessárias para competir em novos mercados e tecnologias que permitem a empresa sobreviver em detrimento das condições do ambiente em que ela se encontra (O'Reilly e Tushman, 2008).

Nesse sentido, não é mais suficiente a escolha por uma ou outra forma de pensamento para liderar, gerenciar e inovar as organizações e a forma como oferecem ou vendem seus serviços e/ou produtos. Ao mesmo tempo em que é preciso analisar os gargalos internos e melhorar continuamente para manter a estabilidade, é necessário também estar atento as novas oportunidades para se diferenciar no mercado e prover um serviço e/ou produto cada vez mais alinhado às expectativas do cliente (Brown \& Wyatt, 2010).

Ao relacionar o conceito da ambidestria organizacional ao contexto da gestão de processos de negócio, o gerenciamento de processos de negócio ambidestro (BPM 
ambidestro) é considerado como um equilíbrio dinâmico entre eficiência e flexibilidade de processos de negócio e se propõe a ter um impacto sobre o desempenho do processo de negócio (ROSEMANN, 2014; XIE, LING e ZHANG, 2011). Enquanto a investigação da eficiência e da flexibilidade tem sido largamente realizada de forma independente, permanece em aberto como a combinação dos pensamentos e técnicas analíticas e intuitivas impactam a análise de processos de negócio (Xie, Ling, e Zhang, 2011).

Uma abordagem que visa a inovação e que se propõe a alinhar o pensamento analítico com o pensamento intuitivo denomina-se Design Thinking (Brown e Wyatt, 2010). Essa abordagem combina a perspectiva do usuário final com a colaboração multidisciplinar e melhoria iterativa para desenvolver processos, produtos e serviços inovadores. Design Thinking cria um ambiente altamente interativo e que promove a aprendizagem através de prototipagem conceitual rápida. A aplicação de Design Thinking na concepção e identificação de oportunidades pode servir como um arcabouço conceitual por meio do uso de técnicas para coletar, analisar e, consequentemente, inovar processos de negócio em iniciativas de BPM (RICHARDSON et al. 2013). Apesar do elevado número de estudos na área de Design Thinking sobre a criação de produtos e serviços inovadores, poucos estudos na área de BPM abordam a utilização de estratégias e técnicas intuitivas para auxiliar na análise, desenho e inovação de processos de negócio alinhados com a expectativa, experiência e satisfação do cliente (ROSEMANN, 2014; RICHARDSON et al. 2013).

Diante desse cenário, o principal objetivo desta pesquisa é investigar como a análise de processo de negócio pode ser realizada para a melhoria dos recursos existentes e a exploração de oportunidades futuras. As questões a seguir guiaram este estudo:

- QP1: Quais são os modelos existentes que exploram as capacidades ambidestras e inovação de processos de negócio?

- QP2: Como sistematizar a análise ambidestra de processos de negócio?

A principal contribuição deste artigo é a construção do método de Análise Ambidestra de Processo de Negócio (A2PN). O restante do artigo está organizado da seguinte forma: Seção 2 apresenta a revisão da literatura; Seção 3 descreve o método de pesquisa; Seção 4 demonstra os trabalhos relacionados; Seção 5 descreve o artefato proposto; Seção 6 apresenta os resultados da avaliação do artefato com especialistas; e a Seção 7 discute as considerações finais e trabalhos futuros.

\section{Revisão da Literatura}

\subsection{Definindo os Conceitos: Análise, Melhoria e Inovação de Processos de Negócio}

A análise de processos de negócio é considerada uma importante fase do ciclo de vida BPM (ABPMP, 2013; MALINOVA, BRINA e MENDLING, 2014). Apesar de haver na literatura diferentes proposições de ciclos BPM, Morais et al. (2014) demonstram que eles não apresentam diferenças fundamentais em termos de atividades e práticas. Numa iniciativa de BPM, a fase de análise acontece após a identificação do processo, entendimento do contexto e da modelagem do estado atual do processo (modelo As-Is) a ser investigado, como pode ser visto na Figura 1. 


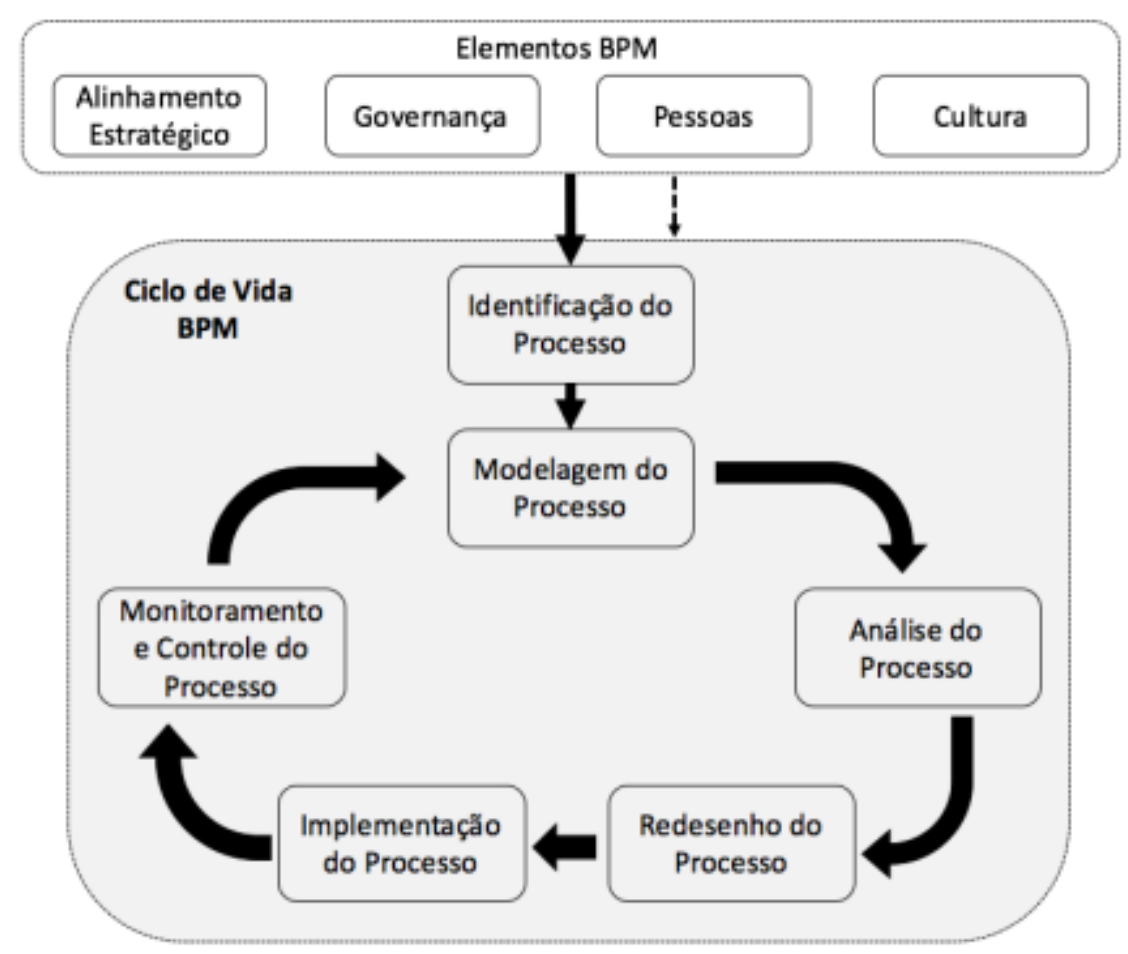

Figura 1. Ciclo de Vida BPM (Malinova, Brina, \& Mendling, 2014)

Considera-se nesta pesquisa que iniciativa de BPM é um tipo de projeto. Como definição, o PMI (2013) cita que um projeto é um esforço temporário empreendido para criar um produto, serviço ou resultado exclusivo. Nesse caso, a iniciativa de BPM é o esforço que deve ser empreendido pela organização e, a partir do seu ciclo de vida, ela deve ser implantada e gerenciada. Como resultado, a organização que está implantando a iniciativa pode focar em alguns objetivos que a gestão de processos de negócio oferece. Após a implantação da iniciativa de BPM, o projeto é finalizado. No entanto, os processos de negócio precisam ser analisados e otimizados continuamente, pois o mercado e as leis podem mudar, como também os objetivos internos e externos.

Durante a iniciativa de BPM são realizadas diversas práticas ao longo das fases de um ciclo de vida BPM. Malinova, Brina e Mendling (2014) definem um conjunto de práticas e atividades para a realização de cada fase apresentada em seu modelo de ciclo de vida BPM. Como este artigo tem como foco a análise de processos, descreve-se a seguir as principais atividades que podem ser realizadas nessa fase de acordo com Malinova, Brina e Mendling (2014):

- Analisar o modelo do processo As-Is com a intenção de levantar a visão geral do ambiente de negócio, propósito do processo, subprocessos e suas interações, requisitos de medição de desempenho, tecnologias de informação, etc.;

- Identificar os problemas existentes do processo As-Is, tais como, lacunas no desempenho do processo, redundâncias, trabalho manual, regras não documentadas, riscos e impactos esperados;

- Priorizar quais problemas devem ser trabalhados;

- Selecionar processos para melhoria.

Conforme discutido na Seção 1, percebe-se acima que os autores se preocupam bastante em analisar os problemas existentes, e deixam de investigar oportunidades de 
inovação dos processos de negócio. Um grande conjunto de abordagens de análise e melhoria de processos foi desenvolvida e é amplamente utilizada há décadas, por exemplo, Lean Management, Teoria das Restrições e Análise de Workflow. Assim como também são utilizadas diversas técnicas analíticas para ampliar a visão geral dos processos, tais como, SIPOC (qual é o contexto do processo?), Análise de Ponto de Vista (quais partes do processo são visíveis para um determinado departamento?), Análise de Cenários (como é o fluxo para fazer pedidos de empréstimos abaixo de mil reais através do sistema?), Análise de Pareto (fazer $20 \%$ de todos os processos explicam $80 \%$ de todas as questões?) ou Simulação de Processos (como é que o processo se comporta sob diferentes situações?).

Pesquisadores e profissionais têm discutido que essas abordagens e técnicas apesar de possuírem bastante eficácia na identificação de problemas existentes, elas não são adequadas para identificar e explorar oportunidades futuras e/ou que estão além de sua fronteira organizacional (ROSEMANN, 2012; ROSEMANN, 2014; RECKER e ROSEMANN, 2014; NIEHAVES e HENSER, 2011; RICHARDSON et al., 2013). Diante da importância de estar atento ao dinamismo do mercado, envolver e entender os clientes, percebe-se cada vez mais a necessidade da utilização dos princípios da Ambidestria Organizacional para coletar dados e analisar os processos de negócio. Com isso, tornará possível a elaboração de processos de negócio tanto de "dentro para fora" como de "fora para dentro" da organização. Nesse contexto, a Associação dos Profissionais de BPM afirma que um dos principais fatores que levam a uma análise bem-sucedida é a consideração do foco do cliente do processo (ABPMP, 2013). Nesse documento, é ressaltado que "Ao tomar a perspectiva do cliente, teremos resultados diferentes na análise; por exemplo: para uma organização, o tempo de ciclo de um atendimento inicia quando o cliente entra em contato, mas para o cliente o tempo de ciclo de atendimento inicia desde o momento que ele decide entrar em contato" (ABPMP, 2013, p. 137).

Pode-se afirmar que a análise de processos está intimamente ligada à análise de negócio. Segundo o Instituto Internacional de Análise de Negócio (IIBA), a análise de negócio é o conjunto de atividades e técnicas utilizadas para servir como ligação entre as partes interessadas, no intuito de compreender a estrutura, políticas e operações de uma organização e para recomendar soluções que permitam que a organização alcance suas metas. Além disso, essa fase envolve compreender como as organizações funcionam e alcançam seus propósitos, e definir as capacidades que uma organização deve possuir para prover produtos e serviços para as partes interessadas externas (IIBA, 2009). Nesse aspecto, a análise de processos de negócio deve ser vista como um meio para gerar valor para a organização, não como um fim (ABPMP, 2013).

Numa iniciativa de BPM, esse valor é traduzido em melhorias para o próprio processo, para a organização e para os seus clientes. Essas melhorias ocorrerão de acordo com os diversos objetivos possíveis das iniciativas de BPM. Ao analisar o framework de avaliação de sucesso BPM proposto por Malinova, Brina e Mendling (2014), uma iniciativa de BPM pode ser executada tendo como motivação um ou mais desses objetivos: identificar e entender o processo, otimizar o processo, aumentar a satisfação do cliente, reduzir custos, reduzir o tempo, assegurar a melhoria contínua, aumentar a produtividade dos funcionários, melhorar a comunicação entre os funcionários, aumentar o conhecimento sobre BPM na organização, consolidar as entradas dos processos, aumentar a transparência, padronizar o processo, gerenciar os 
riscos, medir o processo, alcançar a proatividade do cliente, adaptar-se às mudanças externas, apoiar algum sistema de informação, elaboração de novos processos e desenvolvimento de novos produtos e/ou serviços.

Devido à complexidade do desenho e controle encontrado nas organizações, existe uma necessidade de aplicar as técnicas adequadas de análise de processos (Vergidis, Tiwari, \& Majeed, 2008). Conforme os objetivos definidos para se analisar um processo de negócio, os impactos esperados podem refletir em melhorias de pequeno, médio ou grande porte. Yigt (2013) ressalta que essas melhorias podem ser definidas por inovação incremental, inovação arquitetural e inovação descontínua. A inovação incremental refere-se a pequenas melhorias nos produtos, atividades e processos existentes nas empresas que ajudam a operar com mais eficiência. Inovações arquiteturais referem-se a alterar alguns elementos de negócio, tais como elementos e componentes de base tecnológica e de processo. E a inovação descontínua significa avanços radicais que mudam todo o mercado ou indústria de um determinado segmento.

Nessa mesma linha de pensamento, Schumpeter (1942) classifica inovação em incremental e radical. Essa classificação é baseada em quão significativo o seu efeito será no mercado e o quão reformulador ele será. Refinamento e melhorias no conhecimento existente, nos processos e nos produtos dentro da organização referem-se à inovação incremental. A inovação radical independe da cultura e da rotina da organização na base de conhecimento para acontecer, seu impacto altera as estruturas de mercado existentes. Handerson e Clark (1990) afirmam que não há uma escala precisa para distinguir entre inovação radical e inovação incremental, essa noção pode ser variável e pode depender do tamanho e da finalidade da organização. Em outras palavras, uma inovação radical em uma organização pequena pode ser considerada como inovação incremental em uma grande organização. Implementação de inovações radicais requer mais tempo e recursos do que a incremental (Lin et al., 2013). Inovações incrementais são implementadas em conhecimentos, mercados, produtos, serviços e processos existentes (Tushman e O'Reilly, 1996; Lin et al., 2013).

Outros autores definem esses conceitos na área de BPM utilizando termos diferentes. Harmon e Wolf (2014) afirmam que a melhoria de processos pode utilizar basicamente duas abordagens: melhoria contínua e redesenho (redesign) de processos. A melhoria contínua se caracteriza por uma abordagem que utiliza metodologias evolucionárias. Por sua vez, o redesenho de processos utiliza metodologias revolucionárias (JURISCH et al., 2014). A melhoria contínua é a abordagem mais utilizada nas iniciativas de BPM e seu foco é na busca pela melhoria da eficiência e do desempenho dos processos existentes do ponto de vista "de dentro para fora" (insideout) da organização (Harmon \& Wolf, 2014). Por outro lado, a abordagem revolucionária citada por Jurisch et al. (2014) inclui metodologias que irão identificar e explorar oportunidades no ambiente externo para elaborar novos modelos de processos de negócio.

A ABPMP (2013) cita como metodologias revolucionárias o Redesenho de Processos, a Reengenharia de Processos e a Mudança de Paradigma. A ABPMP categoriza essas metodologias como parte da Transformação de Processos, a qual é mais abrangente que a melhoria contínua de processos em termos de objetivos e impactos para a própria organização e para o cliente. De acordo com Grover e Karkus (2008), a transformação de processos de negócio promove ambientes organizacionais criativos e 
inovadores a fim de lidar com os desafios e oportunidades externas de negócio. A transformação de processos foca sobre processsos de negócio e inclui as perspectivas radicais (reengenharia) e incrementais (melhoria contínua). Para os autores, ambas perspectivas devem ser customizadas para considerar o contexto organizacional e os problemas abordados.

Diante do exposto acima, essa falta de alinhamento conceitual sobre as abordagens que promovem a inovação de processos de negócio pode existir pelo fato de ser ainda um assunto pouco explorado empiricamente e teoricamente, como demonstrado nos trabalhos (NIEHAVES e HENSER, 2011; ROSEMANN, 2012; TANG, PEE e IIJIMA, 2013; ROSEMANN, 2014). Apesar da inconsistência na definição desses conceitos, considera-se importante para o entendimento e condução deste trabalho o crescente direcionamento que as pesquisas recentes têm dado para a utilização combinada das práticas que apoiam tanto a melhoria incremental como melhoria radical dos processos de negócio (LIN, et al., 2013). Com a intenção de padronizar os termos, será utilizado nesta pesquisa o termo melhoria de processos de negócio quando o objetivo for melhorar processos incrementalmente. Por sua vez, o termo inovação de processos de negócio será utilizado em melhorias radicais.

\subsection{Ambidestria Organizacional e Design Thinking}

Ambidestro significa, literalmente, uma pessoa que é capaz de usar as duas mãos com a mesma habilidade. Na literatura de gestão, esse termo é utilizado para indicar a capacidade de uma organização em realizar atividades conflitantes simultaneamente (Gibson e Birkinshaw, 2004). Tushman e O'Reilly (1996) analisaram a evolução histórica de uma grande variedade de empresas e, em seguida, concluiu que a origem do fracasso de algumas empresas e sucesso de outras está na raiz do mesmo problema: se as empresas possuem ou não, a capacidade de operar em dois mercados distintos ao mesmo tempo. Ou seja, se as empresas têm a capacidade de competir em segmentos maduros de mercado através da melhoria contínua e em mercados emergentes através de melhorias radicais.

Nesse aspecto, os princípios da Ambidestria Organizacional referem-se à capacidade de gerenciar componentes complexos e contraditórios, tais como flexibilidade e eficiência, melhoria contínua e inovação radical, alinhamento e adaptação (O'Reilly \& Tushman, 2013). Essas questões tornaram-se mais importante e críticas para as organizações devido a competição agressiva, a necessidade de se adequar as expectativas e satisfação dos clientes, bem como o estresse inconsistente e conflitante entre os departamentos organizacionais em ambientes que mudam rapidamente (Yigit, 2013).

Diante da literatura pesquisada, percebe-se que os elementos mais importantes e que caracterizam a Ambidestria Organizacional são exploration e exploitation (Ling, Zhao, e Wang, 2009; Yigit, 2013; O'Reilly e Tushman, 2013). Exploitation refere-se a produtividade, a eficiência, a seleção, implementação, refinamento e execução; enquanto a exploration refere-se a variação, a experimentação, a criatividade, a flexibilidade, a inovação, o risco e a descoberta (March, 1991). Por não haver uma tradução fiel ao que se corresponde na língua inglesa, neste trabalho o termo exploration será relacionado ao pensamento, práticas e técnicas intuitivas. E o termo exploitation refere-se ao pensamento, práticas e técnicas analíticas. 
Apesar desses dois modelos de pensamento agregarem valor ao negócio organizacional, é difícil a aplicação deles de forma simultânea. Para Martin (2009), as organizações optam, na maioria das vezes, por se concentrar em um modelo de pensamento: analítico ou intuitivo. De acordo com uma pesquisa realizada por Uotila et al. (2009), 80\% das organizações de sua amostra priorizam a estratégia baseada no pensamento analítico, enquanto apenas $20 \%$ ressaltam características intuitivas. Dessa forma, percebe-se que a maioria das organizações possuem características como a eficiência, diminuição de gargalos, produtividade, padronização, dentre outros aspectos. A Tabela 1 demonstra a diferença entre organizações com características analíticas e intuitivas.

Tabela 1. Características Analíticas e Intuitivas (O'Reilly \& Tushman, 2004)

\begin{tabular}{|c|c|c|}
\hline Alinhamento de & Características Analíticas & Características Intuitivas \\
\hline Intenção estratégica & Custo, lucro & Inovação, crescimento \\
\hline Atividades críticas & $\begin{array}{c}\text { Operações, eficiência, } \\
\text { melhoria contínua }\end{array}$ & $\begin{array}{c}\text { Adaptabilidade, novos produtos, } \\
\text { inovação radical }\end{array}$ \\
\hline Competências & Operacional & Empreendedora \\
\hline Estrutura & Formal, mecanicista & Adaptativa, tolerante a erros \\
\hline Controles, recompensas & Margens, produtividade & Marcos, crescimento \\
\hline Cultura & $\begin{array}{c}\text { Eficiência, baixo risco, } \\
\text { qualidade, clientes }\end{array}$ & $\begin{array}{c}\text { Aceita riscos, velocidade, } \\
\text { flexibilidade, experimentação }\end{array}$ \\
\hline Papeis de liderança & Autoritária, top-down & Visionária, envolve stakeholders \\
\hline
\end{tabular}

Com o amadurecimento desses termos e conceitos, é possível encontrar pesquisas recentes nesse sentido atreladas a BPM (Xie, Ling, e Zhang, 2011; Niehaves e Henser, 2011; Rosemann, 2014; Bauer e Leker, 2013; Kohlborn et al. 2014). Rosemann (2014) afirma que os princípios e ideias da Ambidestria Organizacional podem sim ser aplicados ao domínio de BPM. O próprio Rosemann (2014) declara que "Exploitative BPM" utiliza habilidades e técnicas para analisar e avaliar os processos com o objetivo de tanto identificar e quantificar os problemas internos, como melhorar continuamente os processos. Assim como "Explorative BPM" precisa definir muitos objetivos ambiciosos e deve ser capaz de destrinchar o processo ponta-a-ponta a partir dos sentimentos e emoções dos clientes ao comprar ou utilizar produtos e serviços. Com isso, Rosemann (2014) aponta como um caminho futuro de pesquisa para BPM a investigação sobre BPM Ambidestro.

Nesse contexto, assumindo que a análise de processos de negócio também precisa utilizar técnicas e práticas com características analíticas e intuitivas, denominase neste trabalho a análise ambidestra de processos de negócio quando a organização tem a intenção de elaborar modelos de processos de negócio eficientes e alinhados as oportunidades futuras. Chen e Katila (2008, p. 208) ressaltam que práticas analíticas e intuitivas não precisam ser sempre excludentes, mas podem e devem ser complementares. Diante disso, Martin (2009, p. 15) afirma que "as empresas mais bemsucedidas nos próximos anos equilibrarão o domínio analítico (exploitation) e a originalidade intuitiva (exploration) em uma interação dinâmica que eu chamo de Design Thinking".

A abordagem Design Thinking tem sido bastante citada tanto no âmbito profissional quanto no meio acadêmico quando os temas são transformação e inovação de produtos/serviços, processos e modelo de negócio (Luebbe e Weske, 2011). Tornouse comum falar que Design Thinking significa oferecer a qualquer pessoa a capacidade de pensar como um designer. Brown (2008) afirma que Design Thinking é uma 
disciplina que usa a sensibilidade e métodos do Design para atender às necessidades das pessoas com o que é tecnologicamente viável, onde uma estratégia de negócios viável pode ser transformada em valor para o cliente e em oportunidade no mercado.

A adoção de Design Thinking nos negócios está crescendo porque ela ajuda as organizações serem mais inovadoras, a diferenciar de outras marcas e trazer seus produtos e/ou serviços mais rápidos ao mercado. Organizações sem fins lucrativos estão começando também a utilizar Design Thinking para desenvolver melhores soluções para os problemas sociais. Ao trabalhar em estreita colaboração com os cidadãos, essa abordagem permite que as soluções de alto impacto venham de baixo para cima em vez de ser imposta a partir dos mais altos níveis hierárquicos (Brown e Wyatt, 2010).

O processo de Design Thinking consiste de cinco fases: empatia, definição, ideação, prototipação e teste (Brown, 2009). Muitas técnicas e ferramentas disponíveis atualmente tentam auxiliar a execução e a tomada de decisões em cada uma dessas fases. No entanto, Chasanidou, Gasparini e Lee (2014) afirmam que esse aspecto tem recebido pouca atenção em pesquisas sobre Design Thinking. Várias dessas técnicas e ferramentas são desenvolvidas na indústria, tais como IDEO ${ }^{1}$, Oracle $^{2}$ e $\mathrm{SAP}^{3}$. O Instituto de Design de Stanford ${ }^{4}$ também é um dos grandes fomentadores de Design Thinking e contribui bastante com projetos, conhecimentos e técnicas. A seguir, as cinco fases estão sucintamente descritas juntamente com algumas técnicas que podem auxiliar a sua execução.

- Empatia - esta fase é a peça central de um processo de design centrado no ser humano. A empatia auxilia a entender as pessoas dentro do contexto do desafio que está sendo investigado. Seu esforço é para compreender a forma como elas fazem as coisas e por que, quais as suas necessidades físicas e emocionais, como eles pensam sobre o mundo e que é significativo para elas. Técnicas: avaliar o conhecimento preexistente, pesquisa desk, pesquisa exploratória;

- Definição - esta fase visa construir uma base clara e sólida de conhecimento sobre tudo que se aprendeu sobre o cliente e seu contexto. Depois de entender sobre o assunto e ter obtido empatia com as pessoas para as quais se está elaborando a solução, esta fase é sobre gerar sentido a partir da informação coletada através de oportunidades identificadas, também chamadas de insights. Técnicas: cartões de insight, diagrama de afinidades, critérios norteadores, jornada do cliente e personas;

- Ideação - esta fase representa o modo de se concentrar na geração de ideias. Mentalmente, ele representa um processo de "ampliar os horizontes" em termos de conceitos e resultados. Ideação fornece o combustível e também recursos para a construção de protótipos e obter soluções inovadoras para os clientes. Técnicas: brainstorm, cardápio de ideias e matriz de posicionamento;

- Prototipação - esta é a fase em que serão gerados artefatos que mais se aproximam da solução final. Os protótipos devem ser de baixa resolução com

\footnotetext{
${ }^{1}$ Ver http://designthinking.ideo.com/

${ }^{2}$ Ver http://www.oracle.com/technetwork/topics/ux/applications/uxd-1601426.html

${ }^{3}$ Ver https://designthinkingwithsap.com/

${ }^{4}$ Ver http://dschool.stanford.edu/use-our-methods/
} 
uma construção rápida e barata, mas que permita coletar informações úteis através da interação com seus clientes. Um protótipo pode ser qualquer coisa que um usuário pode interagir. Por exemplo, um mural de post-its, um mock-up de software ou até mesmo uma representação visual da experiência do cliente (storyboard). Técnicas: protótipo em papel (Post-its), encenação, storyboard $\mathrm{e}$ mock-ups (Pencil Project ou Balsamiq);

- Teste - nesta fase serão realizados testes junto aos potenciais clientes com os protótipos elaborados. Testar os protótipos é uma nova oportunidade para entender o cliente, mas de forma diferente da fase da Empatia. O foco aqui não é perguntar se o cliente gostou ou não da solução, mas perguntar quantos "por que" forem necessários com a intenção de aprender mais sobre as pessoas e o próprio problema.

Segundo Brown (2009), as fases de Design Thinking estão dispostas como uma progressão linear, mas os desafios do projeto podem ser lidados utilizando as técnicas de acordo com a ordem necessária. Além disso, há um número ilimitado de frameworks de design com os quais se pode trabalhar. O processo com essas cinco fases apresentadas é uma sugestão de um framework. Dessa forma, cada organização irá elaborar o seu próprio processo e adaptá-lo ao seu estilo e forma de trabalhar.

\section{Método de Pesquisa}

Esta pesquisa está baseada numa concepção filosófica de pesquisa pragmática nos termos definidos por Easterbrook et al. (2007) e Creswell (2019). Esta concepção é caracterizada pela preocupação com a solução de problemas, buscando a aplicação "do que funciona" para solução do problema e comporta a combinação de diferentes estratégias de pesquisa. Segundo Marshall (1996), a natureza da pesquisa deve ser classificada de acordo com o tipo do problema que o estudo visa responder. Assim, a abordagem qualitativa é a que melhor se enquadra referente ao problema desta pesquisa, contido na Seção1. A pesquisa qualitativa tem como objetivo investigar o que as pessoas fazem, sabem, pensam, e sentem através de observação, entrevistas, e análise de documentos (PATTON, 2002).

Tendo em vista que o objetivo principal desta pesquisa visa criar um artefato útil para o estado da prática, optou-se pela abordagem de Design Science Research (DSR). DSR foi desenvolvido para pesquisas em Sistemas de Informação, mas os princípios podem ser aplicados em outras áreas de conhecimento. Em suma, esta abordagem fornece uma base adequada para construir um artefato de utilidade, intimamente ligado ao conhecimento existente e um problema relevante no mundo real (WIERINGA, 2010).

A Figura 2 destaca cada fase da pesquisa em termos de: objetivo, questões de pesquisa e método associado ao objetivo. A primeira fase consistiu em responder a (QP1) Quais são os modelos existentes que exploram as capacidades ambidestras e inovação de processos de negócio?. A estratégia de pesquisa adotada foi a pesquisa bibliográfica que permitiu identificar as propostas existentes na literatura. A forma como foi realizada e seus resultados foram apresentados na Seção 4. 


\section{Fase 1 - Identificar modelos existentes que exploram as capacidades}

ambidestras e inovação de processos de negócio.

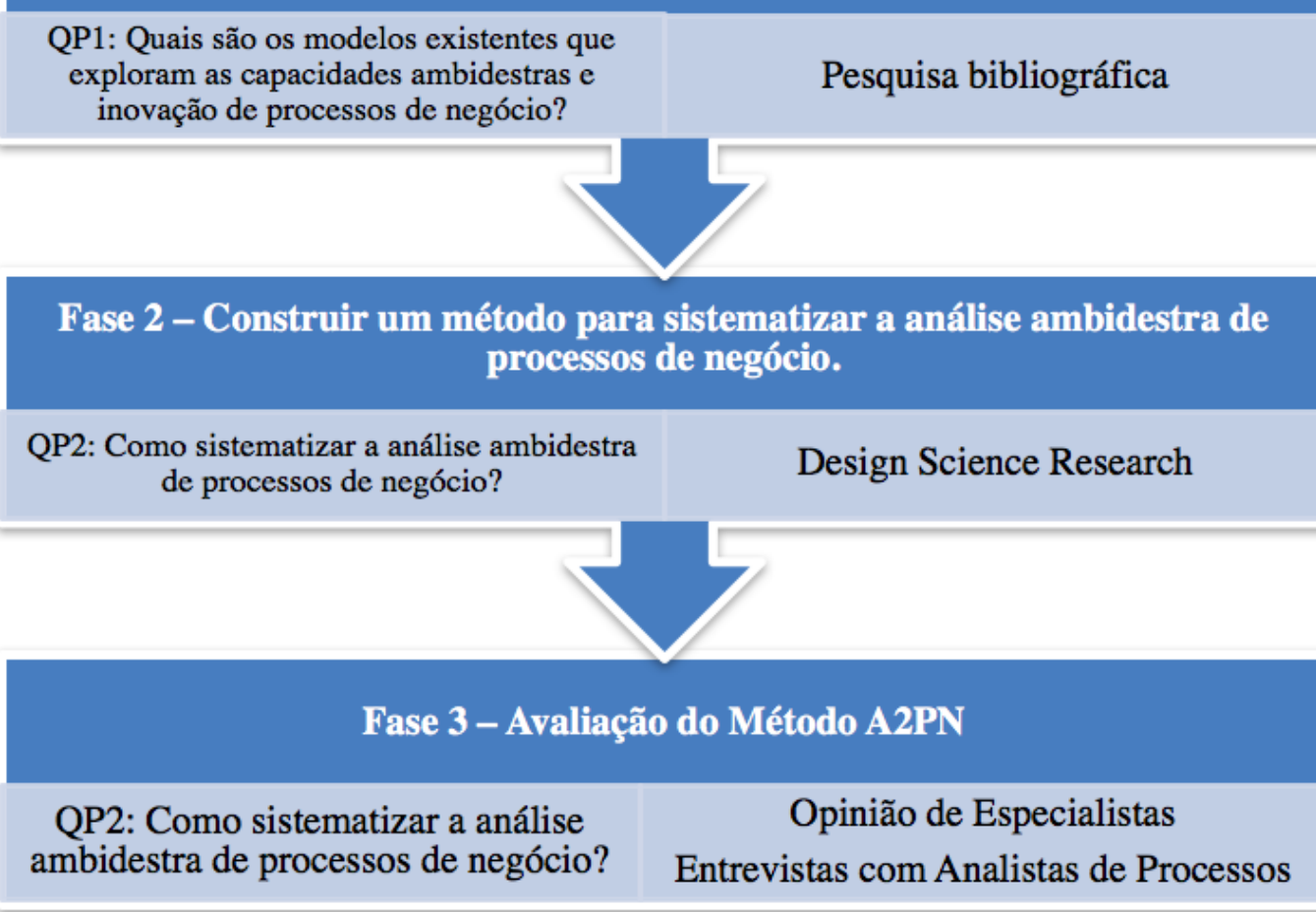

Figura 2. Fases da Pesquisa

A segunda e principal fase da pesquisa concentrou-se em (QP2) Como sistematizar a análise ambidestra de processos de negócio?. A estratégia de pesquisa adotada foi DSR. Hevner et al. (2004) afirmam que os artefatos de DSR podem ser definidos como construtos (vocabulário e símbolos), modelos (abstrações e representações), métodos (algoritmos e práticas) e instanciações (sistemas ou protótipos). Apresentado na Seção 5, o método proposto para sistematização da análise ambidestra de processo de negócio é composto por fases, etapas, atividades, tarefas, técnicas e resultados esperados.

Por fim, a terceira fase da pesquisa contemplou uma avaliação do método proposto e buscou responder também a QP2. Essa avaliação foi realizada por meio da opinião de especialistas e entrevistas com analistas de processo que utilizaram o método em sua organização. Para Wieringa (2014), a opinião de especialistas é a maneira mais simples de avaliar um artefato. $\mathrm{O}$ artefato proposto é submetido a um conjunto de especialistas, que imaginam como tal artefato irá interagir com o contexto imaginado por eles e então prever quais os efeitos que eles pensariam que isso teria. Os especialistas são usados para "observar", por imaginação, a forma como o artefato se comportaria no mundo real.

Nessa avaliação com os especialistas, a disponibilização do artefato foi realizada por meio de um website e solicitou-se que eles avaliassem tanto a usabilidade quanto a utilidade do método de análise ambidestra de processo de negócio proposto. Dessa forma, as instruções foram para que os especialistas percorressem as fases, etapas, atividades, tarefas, técnicas e resultados esperados contidos no método. Em seguida, eles preencheram um questionário semiestruturado que teve como base o Technology Acceptance Model (TAM), demonstrado na Figura 3. 


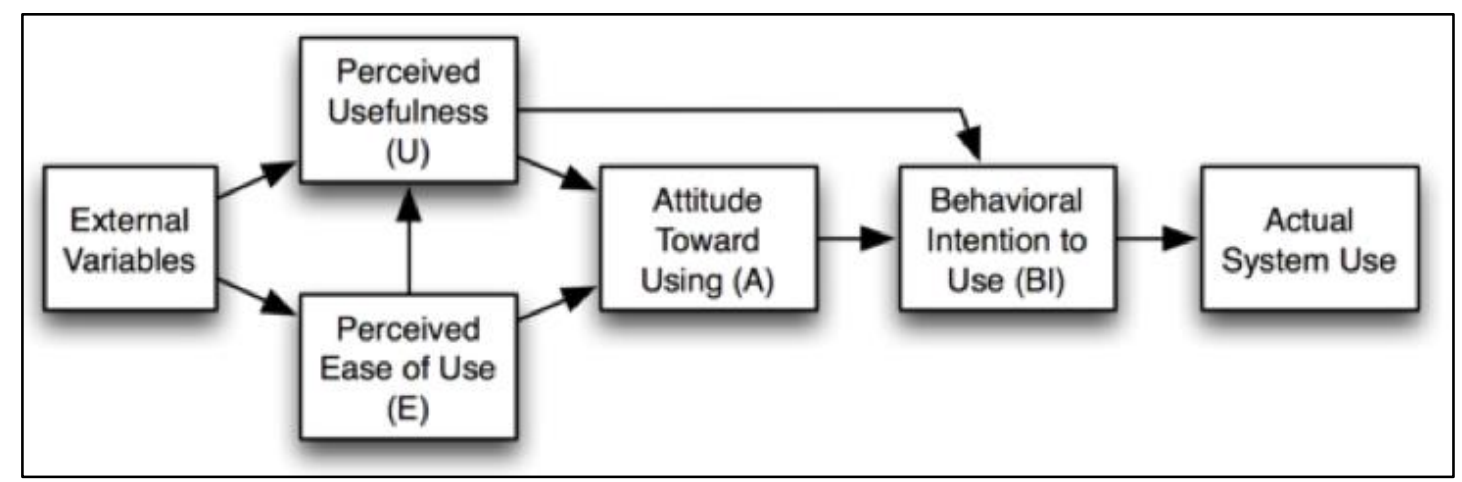

Figura 3. Technology Acceptance Model (Davis, Bagozzi e Warshaw, 1989, p.

985)

Inicialmente, os especialistas preencheram seus dados pessoais, bem como sua formação, experiência com projetos BPM e se já tinha participado de projetos que envolveram Design Thinking, técnicas intuitivas e de criatividade. Em seguida, foram abordadas questões referentes a Facilidade de Entendimento Percebida e Utilidade Percebida. Por fim, questionou-se sobre como foi a experiência geral durante a avaliação do método e como ele poderia ser melhorado. Para participar dessa avaliação, foram selecionados sete especialistas em que se buscou a qualidade nas respostas para a melhoria do método.

Após as sugestões e críticas apresentadas pelos especialistas, o método A2PN foi ajustado e aplicado processo de negócio real. Essa avaliação durou dois meses e teve como objetivo analisar o processo de denúncia de uma organização de esfera estadual. Ao fim da análise, foram realizadas entrevistas semiestruturadas com os três analistas de processo com base nos seguintes critérios: utilidade percebida, facilidade de entendimento, aplicabilidade e limitações do método A2PN. Rubin and Rubin (2011) ressaltam que entrevistas qualitativas semiestruturadas permitem os pesquisadores a realizarem questões planejadas, mas também deixa o espaço livre para discussões abertas. Os resultados dessa fase encontram-se na Seção 6.

Hevner et al. (2004) propôs um framework conceitual com a intenção de organizar, entender, executar e avaliar uma pesquisa DSR. Apresenta-se na Figura 4 a estrutura conforme as características deste trabalho. $\mathrm{O}$ artefato proposto nesta pesquisa tem relevância para organizações públicas e privadas que possuem iniciativas de BPM, que tenham pessoas em sua equipe com conhecimentos em BPM e que estejam dispostos a utilizar post-its, quadros, sites e softwares como meios tecnológicos. A criação do artefato levou em consideração conceitos das áreas de BPM, Design Thinking, Ambidestria Organizacional e do próprio DSR. Como instrumentos de pesquisa, foram utilizados a pesquisa bibliográfica e um questionário semiestruturado. É importante ressaltar que a pesquisa envolveu um processo iterativo de construção, avaliação e refinamento do método proposto. 


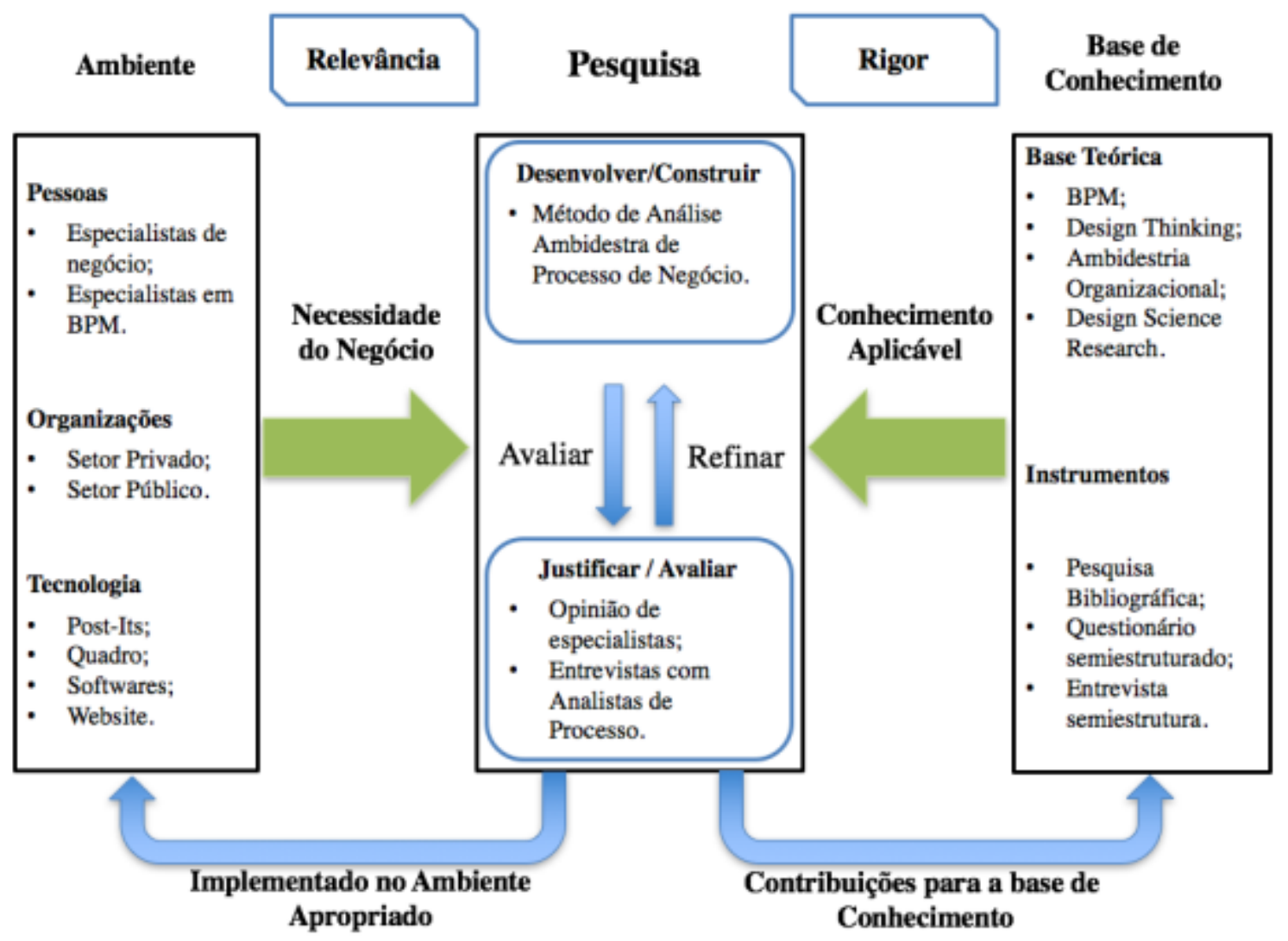

Figura 4. Estrutura da Pesquisa adaptada de (Hevner et al. 2004)

É importante destacar a diferença entre DSR e o desenho de soluções de rotina ou construção de sistemas. De acordo com Hevner et al. (2004), a diferença está na natureza dos problemas e soluções. Para os autores, o desenho de soluções de rotinas é a aplicação do conhecimento existente para resolver problemas organizacionais, tais como a construção de um sistema de informação administrativo ou acadêmico, utilizando as melhores práticas existentes na base de conhecimento para construir os artefatos necessários (construções, modelos, métodos e instanciações). Já a DSR, aborda a pesquisa de solução, de forma única ou inovadora, para problemas importantes ainda não resolvidos, ou mesmo, para problemas que já foram resolvidos, mas não da forma mais eficaz ou eficiente. Assim, o principal diferenciador entre o desenho de soluções de rotina e a DSR é a identificação clara de uma contribuição relevante para a base de conhecimento de fundamentações e metodologias sobre o problema abordado.

Dessa forma, o método para análise ambidestra de processo de negócio pretendido como resultado deste trabalho enquadra-se como desenho de solução de um problema de conhecimento, que está caracterizado na principal questão de pesquisa deste artigo: (QP2) Como sistematizar a análise ambidestra de processos de negócio?

\section{Trabalhos Relacionados}

Com a intenção de situar e justificar esta proposta no âmbito acadêmico, foi realizada uma pesquisa bibliográfica por trabalhos relacionados nas principais bases eletrônicas, tais como, ACM, SCOPUS, IEEE e ScienceDirect. Além dessas bases, trabalhos acadêmicos e whitepapers também foram pesquisados manualmente em jornais $\mathrm{e}$ conferências nas áreas de Sistemas de Informação e Gestão de Processos de Negócio, 
como por exemplo, Revista Brasileira de Sistemas de Informação, Business Process Management Journal, International Conference on Business Management and Electronic Information e Journal of Innovation Management. Foi também realizada a estratégia de pesquisa pearl growing citada por (Ramer, 2005). Essa estratégia é parecida com a estratégia de amostragem "bola de neve", porém o foco do pearl growing é investigar as referências utilizadas pelos artigos mais relevantes e dos principais autores da área.

As palavras-chave pesquisadas nessas bases foram ("business process" OR "business process management" OR "process transformation" OR "process reengineering" OR "process innovation" OR "analysis technique") AND "intuitive thinking" OR "analytical thinking" OR "exploitation" OR "exploration" OR "ambidextrous" OR "ambidexterity"). Conforme a busca realizada, os modelos encontrados (Xie, Ling, e Zhang, 2011; Ling, Zhao, e Wang, 2009; Voigt et al., 2013; Tarafdar e Gordon, 2007; Jurisch et al., 2014) exploram as capacidades ambidestras e inovação de processos de negócio e que serviram de base para a construção do método proposto neste trabalho.

O modelo proposto por (Xie, Ling, e Zhang, 2011) explica como as capacidades organizacionais de Tecnologia da Informação (TI) e as capacidades organizacionais de BPM vão ajudar a desenvolver uma situação propícia para ambidestria em atividades de processos de negócios. Os autores afirmam que capacidades analíticas de TI refere-se à habilidade da organização em gerenciar os recursos de TI existentes para aumentar a produtividade do suporte de TI atual, enquanto que capacidades intuitivas de TI referese à habilidade da organização em capturar novas oportunidades na entrega de suporte de TI para o futuro. Conforme descrito na Figura 5, eles investigaram quais capacidades de BPM são necessárias e como elas podem ser gerenciadas para influenciar o desempenho competitivo da empresa.

Para isso, eles identificaram primeiramente duas práticas de BPM orientadas a valor: eficiência de processo de negócio e flexibilidade de processo de negócio. Baseado nos princípios da ambidestria organizacional, em seguida eles identificaram dois tipos influentes de capacidades de BPM enfatizando TI e aspectos comportamentais das práticas de BPM: a capacidade da gestão dos objetivos dos processos de negócio e a capacidade da gestão das regras de negócio.

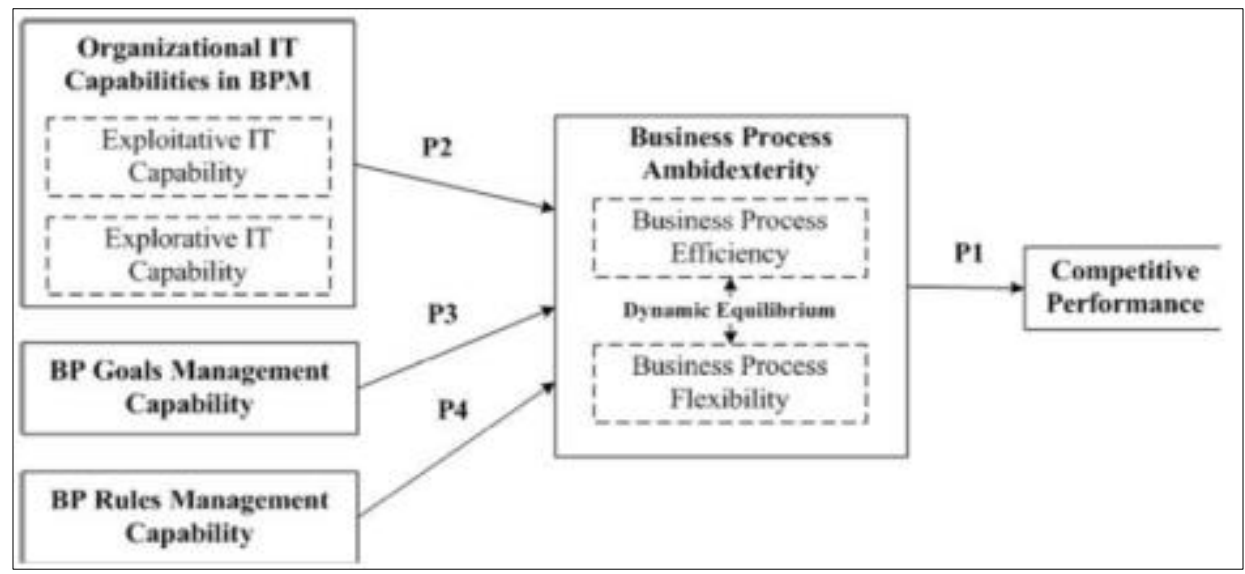

Figura 5. Modelo de (Xie, Ling, e Zhang, 2011) 
Semelhante ao modelo acima, o modelo proposto por (Ling, Zhao, e Wang, 2009) descreve o impacto da sinergia entre processo de negócio e TI através da capacidade ambidestra no desempenho organizacional. O modelo explica que por um lado o relacionamento estreito entre TI e processo de negócio facilita a colaboração de atividades que levam a capacidade de alinhamento ou de eficiência organizacional. Por outro lado, tecnologias da informação emergentes podem ser utilizadas para modularizar o processo tanto quanto possível.

Essa modularização permite que as atividades dos processos possam ser trocadas, compradas e vendidas como partes de um produto e, consequentemente, aumentar a capacidade de adaptação ou de flexibilidade de uma organização. Os autores acreditam que devido a propriedade dinâmica da capacidade ambidestra, ela seria mais significativa em ambientes turbulentos. Como ilustra a Figura 6, eles defendem que a turbulência do ambiente modera o efeito da capacidade ambidestra no desempenho organizacional.

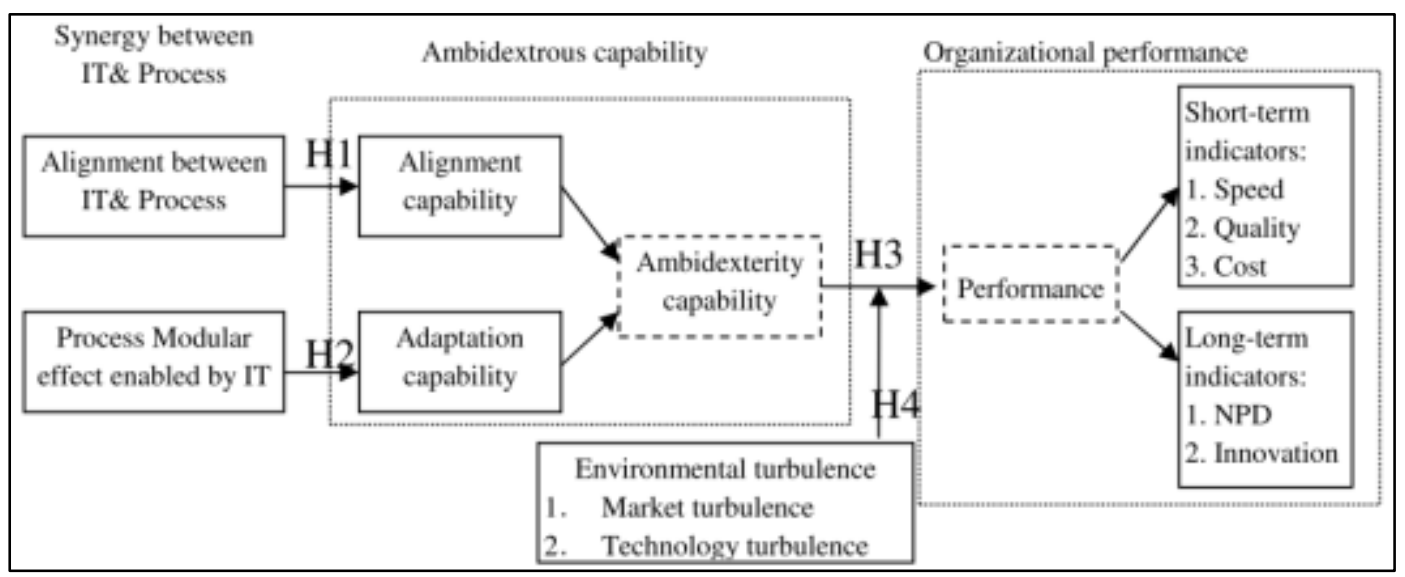

Figura 6. Modelo de (Ling, Zhao, e Wang, 2009)

Considerados também como trabalhos relacionados, os modelos de (Voigt et al., 2013) e (Tarafdar e Gordon, 2007) têm como foco a inovação de processos. O modelo desenvolvido por (VOIGT et al., 2013) investiga e descreve, através das teorias da Capacidade Dinâmica e da Criatividade, os desafios encontrados no desenvolvimento de ferramentas de TI para auxiliar a inovação de processos. Diante disso, eles evidenciaram características derivadas da inovação de processos. Para desenvolver um sistema com esse objetivo, a organização precisa adquirir principalmente três diferentes capacidades. A capacidade para tanto identificar (sensing) necessidades para mudar um processo específico, como também oportunidades externas para criar processos completamente novos. A capacidade de compreender (seizing) todas as atividades relacionadas para melhorar ou desenvolver novos processos e selecionar a alternativa mais promissora. E a capacidade de transformação (transformation) para implementar esses processos dentro da empresa e garantir a sua adoção por todos os stakeholders envolvidos.

Além dessas capacidades, a inovação de processos requer um aprendizado colaborativo e social. A melhoria de um processo não é uma atividade ou responsabilidade de apenas uma pessoa. A partir da perspectiva da gestão de processos, as tarefas ao longo do processo são executadas pelos funcionários, consultores, fornecedores e clientes. Diante disso, Voigt et al. (2013) afirmam que, pelas características da capacidade dinâmica, a inovação de processos deve ocorrer de forma 
colaborativa e pode incluir aprendizado através de atores tanto de dentro como de fora da fronteira organizacional.

Para que ocorra a inovação de processos, os autores sugerem que é preciso seguir um processo de inovação. Ou seja, é necessário seguir um conjunto de atividades (definição do problema, planos de implementação, geração de ideias criativas) para desenvolver algo inovador. Baseados nos conceitos de criatividade, a inovação de processos precisa ter como características a divergência e convergência, ser parcialmente estruturado e ter um clima criativo em que haja uma interação social.

A divergência e a convergência de ideias são fases que estão em todo processo criativo e inovador. De um lado, a divergência tem como foco a coleta de dados e a geração de novas ideias e soluções em grande quantidade. Por outro lado, a convergência permite que esses dados coletados e ideias geradas sejam submetidas à críticas e reflexões para definir o que é mais adequado para o cliente em termos de viabilidade. A inovação de processos também precisa ser parcialmente estruturada devido a imprevisibilidade do fluxo de atividades no desenvolvimento de processos de negócio criativos. Voigt et al. (2013) afirmam que nas fases iniciais em que as ideias são geradas para melhoria ou desenvolvimento de um novo processo, a inovação de processos é vista como desestruturada. No entanto, nas fases seguintes, como a implementação ou simulação do processo, é necessário possuir um alto grau de estruturação.

De acordo com o exposto, os autores do modelo representado na Figura 7 ressaltam que as características derivadas da inovação de processos podem ser agrupadas em duas maiores propriedades: heterogeneidade de tarefa e colaboração. A heterogeneidade condiz com as diferentes áreas de capacidades, o fato do projeto ser desestruturado e estruturado em certos momentos e a habilidade de divergir e convergir sobre os dados e ideias. Por sua vez, a colaboração foi considerada visto que a inovação de processos depende de um alto grau de cooperação entre os stakeholders envolvidos, seja de dentro ou de fora da fronteira organizacional.

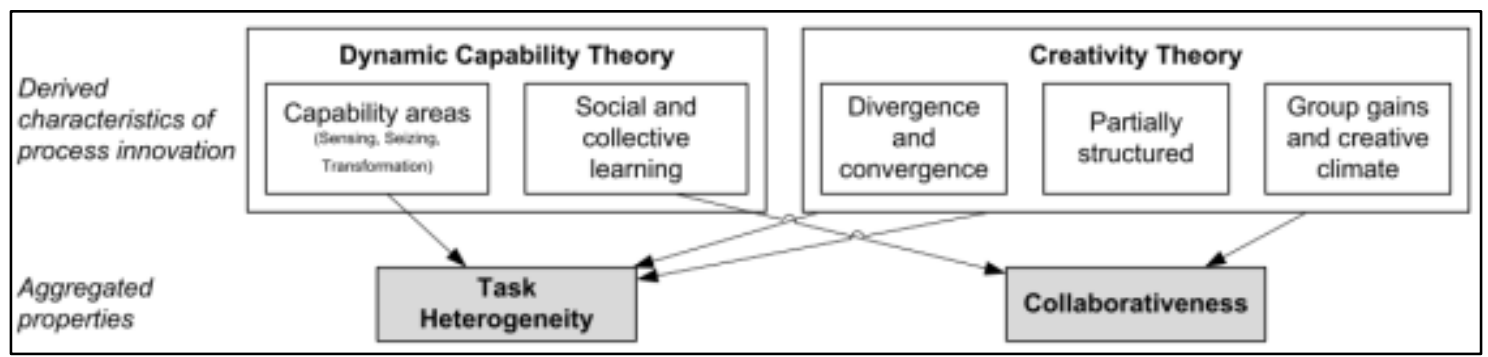

Figura 7. Modelo de (Voigt et al., 2013)

O modelo de (Tarafdar e Gordon, 2007) descreve quais capacidades organizacionais são necessárias para desenvolver projetos de inovação de processos. Para isso, eles pesquisaram na área de Sistemas de Informação (SI) as atividades, papéis e termos que influencie a inovação de processos. Em seguida, realizaram um estudo de caso numa rede de hospitais dos EUA, onde analisaram dois projetos de inovação de processos e como essas as capacidades influenciavam a inovação.

Como pode ser observado na Figura 8, as capacidades organizacionais identificadas na literatura por Tarafdar e Gordon (2007) que influenciam a inovação de processos são: gestão do conhecimento, colaboração, gestão de projeto, ambidestria 
organizacional, governança de TI/Inovação, alinhamento entre negócio e SI e modelagem de processos. De acordo com o estudo realizado, para cada capacidade identificada foi descrito como ela influenciou positivamente a inovação de processos no estudo de caso. A gestão do conhecimento permitiu que as equipes do projeto armazenassem sistematicamente o conhecimento sobre os processos de diferentes fontes internas e externas, e possibilitou o acesso e disseminação do conhecimento. A colaboração facilitou a interação e comunicação entre os clientes e a organização no mapeamento adequado dos processos e permitiu que os usuários finais ficassem devidamente informados sobre o calendário e os planos de projeto.

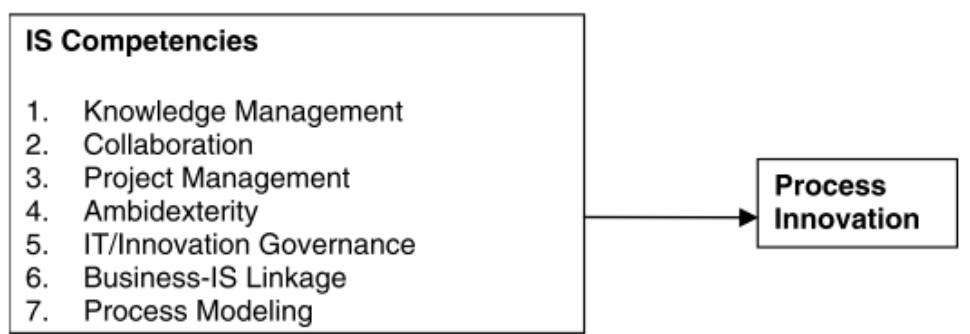

Figura 8. Modelo de (Tarafdar e Gordon, 2007)

A capacidade de gestão de projeto permitiu um gerenciamento adequado dos prazos, recursos, como também dos próprios envolvidos no projeto. A ambidestria organizacional permitiu que a empresa pudesse reconhecer a importância estratégica das inovações e aplicar critérios adequados de avaliação de longo prazo. A governança de TI/inovação permitiu a criação de estruturas e mecanismos para gerenciar efetivamente recursos técnicos e facilitar a inclusão de inovações. O relacionamento entre negócio e SI facilitou o alcance das inovações porque permitiu os profissionais de SI entenderem sobre os aspectos de negócio, como também permitiu os gestores e funcionários entenderem sobre SI.

Apesar da modelagem de processo ter sido evidenciada na literatura, Tarafdar e Gordon (2007) não encontraram presença explícita no estudo de caso realizado. Os autores relatam que isso pode ter acontecido por dois possíveis motivos, o primeiro se deve ao fato de no mesmo momento em que estavam realizando o estudo de caso em um dos hospitais, outras iniciativas de inovação de processos estavam acontecendo em outras unidades desta mesma rede de hospital. O segundo motivo está relacionado como os novos processos e sistemas estavam sendo projetados na unidade hospitalar que estavam investigando, eles perceberam que houve bastante discussão entre a equipe de negócio com os usuários finais sobre as melhorias.

O modelo desenvolvido por (JURISCH et al., 2014) descreve quais capacidades organizacionais são importantes para ter sucesso nas iniciativas de Mudança de Processos de Negócio (do inglês Business Process Change - BPC). Para isso, eles fizeram um survey na literatura de estudos de caso que abordam BPC. Foram analisados ao todo 130 trabalhos que reportaram experiências em projetos desse tipo. Como a Figura 9 apresenta, os resultados da pesquisa demonstram que as capacidades de gestão de projetos, gestão da mudança e de TI têm um impacto positivo no desempenho do projeto de BPC. Além disso, identificaram que as capacidades de TI também influenciam positivamente no desempenho final do processo.

É importante destacar que Jurisch et al. (2014) acreditam que BPC teve origem na Reengenharia de Processos de Negócio (Business Process Reengineering - BPR) e 
na Gestão da Qualidade Total (Total Quality Management - TQM). Eles afirmam que BPR, Inovação de Processos de Negócio e Transformação de Processos de Negócio são geralmente utilizados sinonimamente para o mesmo fenômeno. Dessa forma, iniciativas com esse foco tendem a buscar resultados inovadores radicais e revolucionários. Por outro lado, TQM é considerada uma abordagem para melhoria de processos mais evolucionária, assim como o Six Sigma que promove a melhoria continua de processos. Apesar dessas abordagens (revolucionárias e evolucionárias) possuírem características diferentes, elas podem ser utilizadas de forma complementar para alcançar a melhoria de processos.

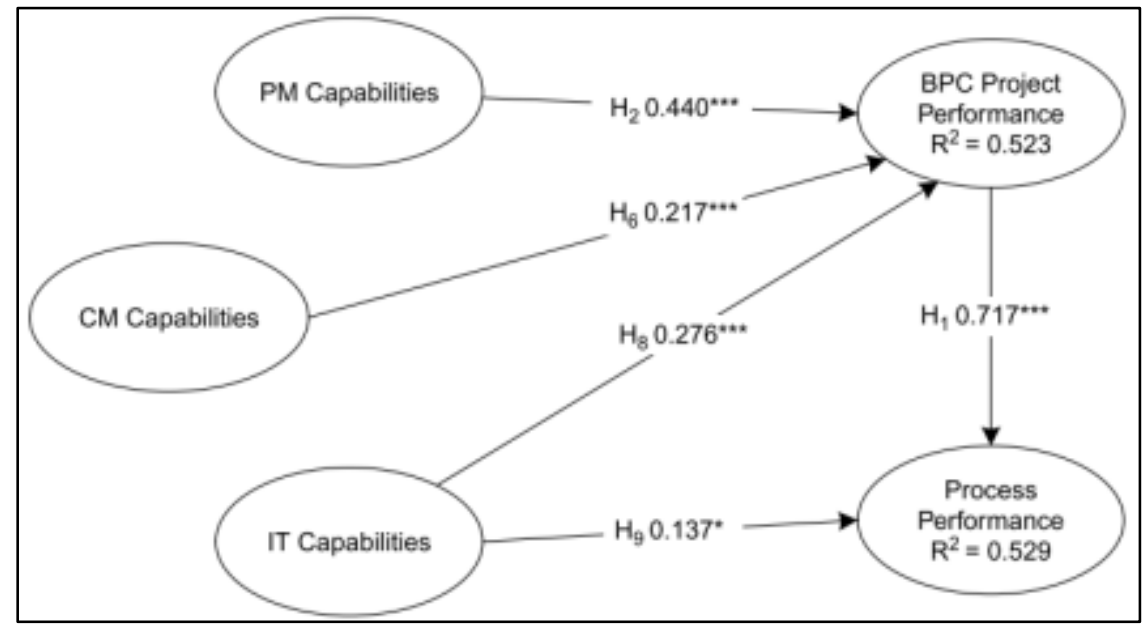

Figura 9. Modelo de (Jurisch et al., 2014)

Para finalizar esta seção, na Tabela 2 é apresentada uma comparação entre os modelos relacionados a esta pesquisa. A comparação é feita utilizando quatro características dos modelos. A primeira se refere ao foco do modelo proposto, a segunda diz respeito as capacidades analíticas (exploitative) e intuitivas (explorative), a terceira contempla as técnicas analíticas e intuitivas e a quarta demonstra se o modelo apresenta ou não uma instanciação do modelo. Ao observar o quadro, percebe-se que a maioria dos modelos relacionados abordam as capacidades organizacionais, tanto analíticas como intuitivas. As que mais se assemelham com o objetivo deste trabalho são as que tem como foco a ambidestria BPM, inovação de processos e mudanças de processos.

Tabela 2. Tabela comparativa dos modelos relacionados

\begin{tabular}{|c|c|c|c|c|c|c|}
\hline \multirow{3}{*}{$\begin{array}{l}\text { Modelos } \\
\text { Conceituais }\end{array}$} & \multirow{3}{*}{ Foco do Modelo } & \multirow{2}{*}{\multicolumn{2}{|c|}{ Capacidades }} & \multirow{2}{*}{\multicolumn{2}{|c|}{ Técnicas }} & \multirow{3}{*}{$\begin{array}{c}\text { Instanciação } \\
\text { e/ou } \\
\text { Guideline }\end{array}$} \\
\hline & & & & & & \\
\hline & & Analí. & Intuit. & Analí. & Intuit. & \\
\hline $\begin{array}{l}\text { (Xie, Ling, \& } \\
\text { Zhang, 2011) }\end{array}$ & $\begin{array}{lr}\begin{array}{l}\text { Capacidades } \\
\text { alcançar }\end{array} & \text { para } \\
\text { ambidestro } & \text { BPM } \\
\end{array}$ & $\mathrm{X}$ & $\mathrm{X}$ & & $\mathrm{X}$ & \\
\hline $\begin{array}{ll}\text { (Ling, } & \text { Zhao, } \\
\& & \text { Wang, } \\
2009) & \end{array}$ & $\begin{array}{l}\text { Alinhamento } \\
\text { Processos e entre } \\
\text { alcançar a capacidade da } \\
\text { ambidestria } \\
\text { organizacional }\end{array}$ & $X$ & $X$ & & & \\
\hline $\begin{array}{l}\text { (VOIGT et al., } \\
\text { 2013) }\end{array}$ & $\begin{array}{l}\text { Capacidades } \\
\text { características para } \\
\text { desenvolver Ferramentas } \\
\text { de TI para alcançar a }\end{array}$ & $\mathrm{X}$ & $\mathrm{X}$ & & $\mathrm{X}$ & $\mathrm{X}$ \\
\hline
\end{tabular}




\begin{tabular}{|l|l|l|l|l|l|l|}
\hline & $\begin{array}{l}\text { inovação de processos de } \\
\text { negócio }\end{array}$ & & & & \\
\hline $\begin{array}{l}\text { Tarafdar \& } \\
\text { Gordon, 2007) }\end{array}$ & $\begin{array}{l}\text { Capacidades de SI para } \\
\text { alcançar a inovação de } \\
\text { processos }\end{array}$ & $\mathrm{X}$ & $\mathrm{X}$ & $\mathrm{X}$ & & \\
\hline $\begin{array}{l}\text { (JURISCH et } \\
\text { al.,2014) }\end{array}$ & $\begin{array}{l}\text { Capacidades para } \\
\text { realizar mudaça de } \\
\text { processos de negócio }\end{array}$ & $\mathrm{X}$ & $\mathrm{X}$ & & & \\
\hline
\end{tabular}

Ao analisar os trabalhos relacionados, percebe-se que todos eles possuem um direcionamento para os benefícios das características ambidestras aplicadas a melhoria e gestão de processos de negócio. No entanto, a lacuna identificada na pesquisa bibliográfica e corroborada por Rosemann (2014) se refere a necessidade específica de analisar os processos de negócio através dos princípios da ambidestria organizacional com a intenção de tanto identificar os problemas internos às organizações como também explorar oportunidades no meio externo. De acordo com essa necessidade, julga-se necessário o desenvolvimento de um método que sistematize a análise ambidestra de processos de negócio.

\section{Artefato Proposto: Método para Análise Ambidestra de Processo de Negócio}

Nesta seção, descreve-se o artefato proposto nesta pesquisa configurado como um método de acordo com a Design Science Research e que visa responder a QP2: Como sistematizar a análise ambidestra de processos de negócio?. Segundo March e Smith (1995), método é um conjunto de passos necessário para desempenhar uma determinada tarefa. Pode ser representado graficamente ou encapsulado em heurísticas e algoritmos específicos. Os métodos favorecem tanto a construção quanto a representação das necessidades de melhoria de um fenômeno num determinado contexto.

Nesse sentido, afirma-se que o método para Análise Ambidestra de Processo de Negócio (A2PN) é indicado para organizações que possuem o nível básico de conhecimento sobre BPM e queiram melhorar e/ou inovar seus processos de negócio. Sua construção teve como base os elementos e fundamentos identificados nos modelos conceituais descritos na Seção 4. A utilização do A2PN tem como principal entrada o modelo atual (As-Is) do processo de negócio a ser analisado e terá como principal saída uma documentação que auxiliará a equipe responsável no desenho de um novo modelo de processo levando em consideração os pensamentos analítico e intuitivo. Pelo fato do pensamento intuitivo levar bastante em consideração a perspectiva de fora para dentro, considera-se que o método é mais adequado para processos que começam e terminam no cliente da organização.

Com a intenção de sistematizar a análise de processo de negócio, o método foi categorizado em fases, etapas, atividades, tarefas, técnicas e resultados esperados. Essa categorização foi elaborada com base no $\mathrm{PMBoK}$, onde as fases fazem referência aos grupos de processos (iniciação, planejamento, execução, monitoramento e encerramento); as tarefas são as entradas (inputs); as técnicas são as ferramentas; e os resultados esperados são as saídas (PMI, 2013).

Dessa forma, foram definidas três fases para a utilização do A2PN: planejamento, realização e encerramento. A fase de planejamento tem como objetivo 
criar o plano de análise para guiar toda a sua execução. A fase de execução foi categorizada em etapas de acordo com a abordagem Design Thinking: imersão, definição, ideação e prototipação. Assim, na fase de execução são realizadas atividades e tarefas por meio de técnicas analíticas e intuitivas para identificar problemas existentes e explorar oportunidades futuras. Por fim, a fase de encerramento se caracteriza pela revisão dos dados coletados e geração da documentação final da análise de processo de negócio. Sugere-se que algum órgão, como o escritório de processos, ou o gerente do projeto faça o monitoramento e controle da iniciativa de BPM em que a análise está sendo realizada.

A proposta desta pesquisa é disponibilizar o A2PN para que qualquer pessoa com noções básicas em BPM consiga executá-lo sem ajuda de um especialista. No entanto, acredita-se que a profundidade e qualidade dos resultados das técnicas dependerá da experiência dos seus usuários. Além disso, a quantidade de técnicas e o tempo necessário para executar o método dependerá também do tamanho $\mathrm{e}$ complexidade do processo a ser analisado. Ressalta-se que a principal justificativa para a inclusão de práticas e técnicas intuitivas refere-se capacidade de estimular o pensamento divergente e convergente na geração de ideias para tornar o processo de negócio alinhado às expectativas do cliente.

Para facilitar o aprendizado, o método foi disponibilizado tanto em BPMN, como também em formato de imagem em que deixa explícito as fases, atividades, tarefas, técnicas e resultados esperados. A representação do método em formato $\mathrm{BPMN}^{5}$ permite que os usuários percorram sequencialmente todo o fluxo de atividades em seu primeiro nível. Ao expandir cada atividade, o usuário visualizará as tarefas correspondentes bem como as técnicas adequadas e os resultados esperados para cada tarefa.

No website $^{6}$ em que foi disponibilizado o método é possível visualizar as imagens correspondentes as fases, etapas, atividades, tarefas, técnicas e resultados esperados. Ao clicar nas miniaturas referente as fases, o usuário é direcionado a uma página específica em que são detalhados os demais elementos do método. Apresenta-se nas Tabelas 3, 4 e 5 as fases de Planejamento, Execução e Encerramento, bem como todos os elementos que compõem o método A2PN. Como existem diversos tipos de objetivos para se analisar um processo de negócio, as técnicas dispostas no método são apresentadas como sugestão aos usuários de acordo com os resultados esperados das tarefas a serem realizadas. As técnicas intuitivas estão mais presentes na fase de Execução pelo fato de ter sido organizada conforme a abordagem Design Thinking. Diante disso, pode-se perceber que nem sempre são sugeridas técnicas analíticas ou intuitivas para determinadas tarefas.

Tabela 3. Fase de Planejamento da Análise Ambidestra de Processo de Negócio

\begin{tabular}{|l|l|c|c|l|}
\hline Atividade & \multicolumn{1}{|c|}{ Tarefas } & $\begin{array}{c}\text { Técnicas } \\
\text { Analíticas }\end{array}$ & $\begin{array}{c}\text { Técnicas } \\
\text { Intuitivas }\end{array}$ & $\begin{array}{c}\text { Resultado } \\
\text { Esperado }\end{array}$ \\
\hline $\begin{array}{l}\text { Definir a } \\
\text { equipe de } \\
\text { análise }\end{array}$ & $\begin{array}{l}\text { Selecionar as pessoas que irão } \\
\text { conduzir a análise do processo; } \\
\text { Definir os os papéis }\end{array}$ & $\begin{array}{c}\text { Workshop } \\
\text { com } \\
\text { stakeholders }\end{array}$ & & $\begin{array}{l}\text { Lista da equipe } \\
\text { de análise, } \\
\text { papéis e }\end{array}$ \\
\hline
\end{tabular}

\footnotetext{
${ }^{5}$ Representação do método em formato BPMN: http://goo.gl/wZAFUL

${ }^{6}$ Website que o método foi disponibilizado http://goo.gl/WDGKC9 


\begin{tabular}{|c|c|c|c|c|}
\hline & $\begin{array}{l}\text { responsabilidades de cada pessoa na } \\
\text { análise do processo; } \\
\text { Definir as estratégias da análise do } \\
\text { processo. }\end{array}$ & & & $\begin{array}{l}\text { responsabilidad } \\
\text { es, e as } \\
\text { estratégias de } \\
\text { análise. }\end{array}$ \\
\hline $\begin{array}{l}\text { Entender o } \\
\text { ambiente } \\
\text { de negócio }\end{array}$ & $\begin{array}{l}\text { Reunir informações estratégicas } \\
\text { sobre a organização e o processo de } \\
\text { negócio, tais como, planejamento } \\
\text { estratégico, posicionamento da } \\
\text { cadeia de valor, criticidade, riscos, } \\
\text { oportunidades e ameaças; } \\
\text { Realizar benchmarking relacionado } \\
\text { ao processo; } \\
\text { Promover um entendimento } \\
\text { comum com todos os membros da } \\
\text { equipe de análise. }\end{array}$ & $\begin{array}{c}\text { Workshop } \\
\text { com } \\
\text { stakeholders, } \\
\text { Entrevistas e } \\
\text { Análise } \\
\text { documental }\end{array}$ & & $\begin{array}{l}\text { Descrição do } \\
\text { Ambiente de } \\
\text { Negócio }\end{array}$ \\
\hline $\begin{array}{l}\text { Estabelecer } \\
\text { o escopo } \\
\text { da análise }\end{array}$ & $\begin{array}{l}\text { Descrever o desafio e os objetivos } \\
\text { da análise do processo; } \\
\text { Determinar a profundidade da } \\
\text { análise de acordo com os os } \\
\text { objetivos definidos, recursos } \\
\text { existentes, sistemas, funções e } \\
\text { pessoas envolvidas; } \\
\text { Definir indicadores da análise; } \\
\text { Escrever um resumo sobre o } \\
\text { desafio da análise do processo. }\end{array}$ & $\begin{array}{c}\text { Workshop } \\
\text { com } \\
\text { stakeholders }\end{array}$ & $\begin{array}{c}\text { Brainstorming } \\
\text { e } \\
\text { Brainwriting }\end{array}$ & $\begin{array}{l}\text { Compilação de } \\
\text { Documentos } \\
\text { Relevantes }\end{array}$ \\
\hline $\begin{array}{l}\text { Criar o } \\
\text { plano de } \\
\text { análise }\end{array}$ & $\begin{array}{l}\text { Listar as principais atividades da } \\
\text { Análise do Processo de Negócio; } \\
\text { Elaborar um cronograma da } \\
\text { Análise do Processo; } \\
\text { Iniciar a elaboração do Plano de } \\
\text { Análise do processo de negócio } \\
\text { alinhado com o planejamento do } \\
\text { projeto; } \\
\text { Apresentar o Plano de Análise aos } \\
\text { membros da Equipe de Análise com } \\
\text { a intenção de alinhar o escopo e } \\
\text { coletar expectativas. }\end{array}$ & $\begin{array}{l}\text { Workshop } \\
\text { com } \\
\text { stakeholders }\end{array}$ & & $\begin{array}{l}\text { Primeira } \\
\text { versão do } \\
\text { Plano de } \\
\text { Análise }\end{array}$ \\
\hline
\end{tabular}

Como dito anteriormente, a fase de realização da análise foi categorizada em quatro etapas conforme a abordagem Design Thinking. Na Tabela 4 são apresentadas as atividades, tarefas, técnicas e resultados esperados das etapas de Imersão, Definição, Ideação e Prototipação.

Tabela 4. Fase de Realização da Análise Ambidestra de Processo de Negócio

\begin{tabular}{|c|l|c|c|c|}
\hline \multicolumn{5}{|c|}{ ETAPA DE IMERSÃo } \\
\hline Atividade & \multicolumn{1}{|c|}{ Tarefas } & $\begin{array}{c}\text { Técnicas } \\
\text { Analíticas }\end{array}$ & $\begin{array}{c}\text { Técnicas } \\
\text { Intuitivas }\end{array}$ & $\begin{array}{c}\text { Resultado } \\
\text { Esperado }\end{array}$ \\
\hline $\begin{array}{c}\text { Revisar o } \\
\text { processo de } \\
\text { negócio }\end{array}$ & $\begin{array}{l}\text { Revisar o escopo da análise; } \\
\text { Alinhar o conhecimento sobre o } \\
\text { processo de negócio. }\end{array}$ & $\begin{array}{c}\text { Reunião } \\
\text { com a } \\
\text { equipe de } \\
\text { análise }\end{array}$ & & $\begin{array}{c}\text { Lista da equipe } \\
\text { de análise, } \\
\text { papéis e as } \\
\text { estratégias de } \\
\text { análise. }\end{array}$ \\
\hline $\begin{array}{c}\text { Preparar a } \\
\text { coleta dos } \\
\text { dados do } \\
\text { processo }\end{array}$ & $\begin{array}{l}\text { Definir o ambiente a ser } \\
\text { pesquisado } \\
\text { Selecionar os atores e clientes do } \\
\text { processo de negócio que serão }\end{array}$ & $\begin{array}{c}\text { Reunião } \\
\text { com a } \\
\text { equipe de } \\
\text { análise }\end{array}$ & & $\begin{array}{c}\text { Descrição do } \\
\text { Ambiente de } \\
\text { Negócio }\end{array}$ \\
\hline
\end{tabular}




\begin{tabular}{|c|c|c|c|c|}
\hline & $\begin{array}{l}\text { entrevistados ou observados; } \\
\text { Planejar coleta de dados: } \\
\text { definição do roteiro e organização } \\
\text { do materiais para a coleta dos } \\
\text { dados. }\end{array}$ & & & \\
\hline \multirow{4}{*}{$\begin{array}{l}\text { Aprender } \\
\text { sobre o } \\
\text { modelo atual } \\
\text { (AS-IS) do } \\
\text { processo }\end{array}$} & $\begin{array}{l}\text { Aprender com os atores do } \\
\text { processo }\end{array}$ & $\begin{array}{l}\text { Entrevistas, } \\
\text { Pesquisa } \\
\text { documental } \\
\text { ou Folhas de } \\
\text { Verificação }\end{array}$ & $\begin{array}{l}\text { Entrevista } \\
\text { com empatia, } \\
\text { Câmera do } \\
\text { usuário, } \\
\text { Diário de } \\
\text { bordo }\end{array}$ & \multirow{4}{*}{$\begin{array}{l}\text { Documentação } \\
\text { sobre tudo que } \\
\text { envolve o } \\
\text { processo de } \\
\text { negócio }\end{array}$} \\
\hline & $\begin{array}{l}\text { Aprender com os clientes do } \\
\text { processo }\end{array}$ & & $\begin{array}{l}\text { Entrevista } \\
\text { com empatia, } \\
\text { Câmera do } \\
\text { usuário, } \\
\text { Diário de } \\
\text { bordo }\end{array}$ & \\
\hline & Aprender com especialistas & $\begin{array}{l}\text { Entrevistas } \\
\text { com } \\
\text { empresas } \\
\text { similares } \\
\end{array}$ & & \\
\hline & Analisar ambientes similares & $\begin{array}{l}\text { Entrevistas } \\
\text { com } \\
\text { especialistas } \\
\end{array}$ & & \\
\hline \multicolumn{5}{|c|}{ ETAPA DE DEFINIÇÃO } \\
\hline Atividade & Tarefas & $\begin{array}{c}\text { Técnicas } \\
\text { Analíticas }\end{array}$ & $\begin{array}{l}\text { Técnicas } \\
\text { Intuitivas }\end{array}$ & $\begin{array}{l}\text { Resultado } \\
\text { Esperado }\end{array}$ \\
\hline $\begin{array}{l}\text { Compartilhar } \\
\text { o aprendizado }\end{array}$ & $\begin{array}{l}\text { Registrar os aprendizados } \\
\text { obtidos na coleta dos dados; } \\
\text { Discutir sobre os aprendizados } \\
\text { entre os membros da equipe de } \\
\text { análise. }\end{array}$ & $\begin{array}{l}\text { Elaboração } \\
\text { de relatórios } \\
\text { analíticos } \\
\text { sobre a } \\
\text { coleta de } \\
\text { dados }\end{array}$ & $\begin{array}{l}\text { Mapa da } \\
\text { empatia }\end{array}$ & $\begin{array}{l}\text { Alinhamento } \\
\text { sobre as } \\
\text { informações } \\
\text { coletadas }\end{array}$ \\
\hline $\begin{array}{l}\text { Categorizar os } \\
\text { aprendizados }\end{array}$ & $\begin{array}{l}\text { Categorizar os aprendizados em } \\
\text { temas, critérios e personas; } \\
\text { Definir as oportunidades de } \\
\text { melhorias do processo. }\end{array}$ & & \multirow{2}{*}{$\begin{array}{l}\text { Cartões de } \\
\text { insights, } \\
\text { Diagrama de } \\
\text { afinidades, } \\
\text { Critérios } \\
\text { norteadores, } \\
\text { personas e } \\
\text { jornada do } \\
\text { usuário }\end{array}$} & $\begin{array}{l}\text { Lista de } \\
\text { melhorias } \\
\text { incrementais } \\
\text { e/ou radicais }\end{array}$ \\
\hline $\begin{array}{l}\text { Estruturar as } \\
\text { oportunidades } \\
\text { identificadas }\end{array}$ & $\begin{array}{l}\text { Discutir as oportunidades } \\
\text { identificadas; } \\
\text { Transformar as oportunidades } \\
\text { identificadas em questões para } \\
\text { ideação. }\end{array}$ & & & $\begin{array}{l}\text { Lista de ações } \\
\text { para cada } \\
\text { melhoria } \\
\text { incremental } \\
\text { e/ou radical }\end{array}$ \\
\hline \multicolumn{5}{|c|}{ ETAPA DE IDEAÇÃO } \\
\hline Atividade & Tarefas & $\begin{array}{c}\text { Técnicas } \\
\text { Analíticas }\end{array}$ & $\begin{array}{l}\text { Técnicas } \\
\text { Intuitivas }\end{array}$ & $\begin{array}{l}\text { Resultado } \\
\text { Esperado }\end{array}$ \\
\hline Gerar ideias & $\begin{array}{l}\text { Selecionar as questões para } \\
\text { serem discutidas; } \\
\text { Preparar o ambiente para } \\
\text { ideação; } \\
\text { Realizar ideação para gerar as } \\
\text { melhorias incrementais e radicais; } \\
\text { Selecionar melhores ideias. }\end{array}$ & \multirow[t]{2}{*}{$5 \mathrm{~W} 2 \mathrm{H}$} & \multirow{2}{*}{$\begin{array}{l}\text { Brainstorming } \\
\text { Brainwriting, } \\
\text { Cardápio de } \\
\text { ideias, Matriz } \\
\text { de } \\
\text { posicionamen- } \\
\text { to. }\end{array}$} & \multirow[t]{2}{*}{$\begin{array}{l}\text { Documentação } \\
\text { das ideias a } \\
\text { serem } \\
\text { prototipadas }\end{array}$} \\
\hline Refinar ideias & $\begin{array}{l}\text { Verificar viabilidade das ideias; } \\
\text { Listar obstáculos; } \\
\text { Explorar e discutir novas ideias; }\end{array}$ & & & \\
\hline
\end{tabular}

SANTOS, H. R. M.; ALVES, C. F.

Explorando a Ambidestria Organizacional e Design Thinking na Análise de Processos de Negócio isys | Revista Brasileira de Sistemas de Informação, Rio de Janeiro, vol. 9, No. 4, pp. 101-138, 2016 


\begin{tabular}{|c|c|c|c|c|}
\hline & Descrever as ideias. & & & \\
\hline \multicolumn{5}{|c|}{ ETAPA DE PROTOTIPAÇÃO } \\
\hline Atividade & Tarefas & $\begin{array}{c}\text { Técnicas } \\
\text { Analíticas } \\
\end{array}$ & $\begin{array}{c}\text { Técnicas } \\
\text { Intuitivas } \\
\end{array}$ & $\begin{array}{l}\text { Resultado } \\
\text { Esperado }\end{array}$ \\
\hline $\begin{array}{l}\text { Elaborar } \\
\text { versão inicial } \\
\text { do modelo } \\
\text { proposto (To } \\
\text { Be) do } \\
\text { processo }\end{array}$ & $\begin{array}{l}\text { Desenvolver visões do processo } \\
\text { de negócio; } \\
\text { Elaborar modelo proposto (To } \\
\text { Be) do processo em BPMN. }\end{array}$ & $\begin{array}{l}\text { Modelagem } \\
\text { de processo }\end{array}$ & $\begin{array}{c}\text { Storyboards, } \\
\text { encenações, } \\
\text { protótipo em } \\
\text { papel, } \\
\text { protótipo de } \\
\text { serviços, } \\
\text { diagrama }\end{array}$ & $\begin{array}{l}\text { Versões } \\
\text { iniciais do } \\
\text { modelo } \\
\text { proposto do } \\
\text { processo de } \\
\text { negócio }\end{array}$ \\
\hline $\begin{array}{l}\text { Obter } \\
\text { feedback }\end{array}$ & $\begin{array}{l}\text { Selecionar stakeholders; } \\
\text { Elaborar roteiro do feedback; } \\
\text { Realizar conversa de feedback; } \\
\text { Documentar a interação do } \\
\text { feedback; } \\
\text { Agregar o feedback às ideias. }\end{array}$ & & & $\begin{array}{c}\text { Documentação } \\
\text { das versões } \\
\text { iniciais do } \\
\text { modelo } \\
\text { proposto }\end{array}$ \\
\hline
\end{tabular}

Por fim, na Tabela 5 é apresentada a fase de encerramento da análise em que contempla as atividades de revisar e desenvolver a documentação final da análise do processo.

Tabela 5. Fase de Encerramento da Análise Ambidestra de Processo de Negócio

\begin{tabular}{|l|l|l|l|l|}
\hline \multicolumn{1}{|c|}{ Atividade } & \multicolumn{1}{|c|}{ Tarefas } & $\begin{array}{c}\text { Técnicas } \\
\text { Analíticas }\end{array}$ & $\begin{array}{c}\text { Técnicas } \\
\text { Intuitivas }\end{array}$ & \multicolumn{1}{c|}{$\begin{array}{c}\text { Resultado } \\
\text { Esperado }\end{array}$} \\
\hline $\begin{array}{l}\text { Revisar } \\
\text { Documentação }\end{array}$ & $\begin{array}{l}\text { Revisar toda a documentação } \\
\text { gerada na fase de execução da } \\
\text { análise do processo de negócio. }\end{array}$ & $\begin{array}{c}\text { Workshop } \\
\text { com } \\
\text { stakeholders }\end{array}$ & $\begin{array}{l}\text { Documentação } \\
\text { da análise } \\
\text { revisada }\end{array}$ \\
\hline $\begin{array}{l}\text { Desenvolver } \\
\text { Documentação } \\
\text { final da }\end{array}$ & $\begin{array}{l}\text { Organizar os aprendizados, } \\
\text { ideias, insights, modelo To Be e } \\
\text { Análise de } \\
\text { Processo }\end{array}$ & $\begin{array}{l}\text { Gerar decumentação final da protótipos; } \\
\text { análise do processo. }\end{array}$ & & $\begin{array}{l}\text { Documentação } \\
\text { da análise } \\
\text { concluída }\end{array}$ \\
\hline
\end{tabular}

Pelo fato de muitos analistas de processos e profissionais de BPM ainda não conhecerem ou dominarem a operacionalização das técnicas intuitivas sugeridas, foi disponibilizado no método um menu específico que apresenta as técnicas e um fluxo a ser seguido ao longo da análise ambidestra de processo de negócio. Além disso, ao clicar no título da técnica desejada, o usuário é direcionado a uma página específica em que detalha o que é a técnica, porque utilizá-la, como utilizá-la e os participantes que podem executá-la.

É importante ressaltar que não faz parte do escopo desta pesquisa investigar quais as melhores técnicas para cada atividade proposta no método. Conforme citado na Seção 2.2, da mesma forma existem muitas técnicas analíticas, diversas técnicas intuitivas têm sido desenvolvidas pela academia e pela indústria. Porém, a aplicação das técnicas intuitivas na análise e melhoria de processos de negócio ainda é um tema emergente na literatura. Segundo Rosemann (2014), no atual cenário, os analistas de processos desconhecem a abordagem Design Thinking e/ou nunca tiveram experiência na utilização de técnicas intuitivas nesse contexto 
Com a intenção de não tornar o método cansativo para o usuário a ponto de fazê-lo passar o bom tempo aprendendo como utilizar várias técnicas intuitivas existentes, foram sugeridas 16 técnicas intuitivas para compor o método ao longo da fase de execução da análise ambidestra de processo de negócio. Na etapa de imersão, a proposta é que os analistas de processo de negócio aprendam de fato sobre tudo que envolve o processo. Na perspectiva de foco do cliente, é importante perceber que o processo de negócio se inicia no momento em que ele está decidindo qual produto ou serviço adquirir. Além disso, a expectativa e experiência do cliente quanto ao processo que está demandando são variáveis importantes para a melhoria do produto e/ou serviço oferecido. Dessa forma, técnicas intuitivas como a entrevista com empatia e câmera do usuário podem auxiliar nesse aspecto. Pesquisas documentais e folhas de verificação são técnicas analíticas que podem auxiliar na identificação de retrabalhos, possibilidade de automação de atividades, entre outros aspectos relacionados a gargalos e problemas existentes no processo.

Após a equipe de análise ter coletado dados de como o processo acontece por meio de diferentes perspectivas, a etapa de definição auxiliará na categorização desses dados e listará melhorias e ações a serem discutidas na etapa de ideação. Dessa forma, relatórios analíticos contendo os principais problemas e gargalos relacionados a tempo, custo e qualidade são elaborados com base nos documentos pesquisados e entrevistas realizadas. Com o apoio das técnicas intuitivas, como mapa da empatia, cartões de insights, personas e jornada do usuário, torna-se possível ampliar as oportunidades de melhoria ao longo do processo de negócio. Pois, elas permitem aos analistas de processo olhar além da fronteira organizacional e enxergar dados subjetivos que não possíveis coletar por meio de técnicas analíticas, tais como, sentimentos e emoções dos atores e clientes do processo.

É parte da análise do processo a discussão das ideias e a documentação de como elas poderão ser desenvolvidas. Nesse sentido, a etapa de ideação é responsável por selecionar as melhores ideias geradas de acordo com a viabilidade e obstáculos existentes. A técnica analítica 5W2H é bastante utilizada para definir ações sobre o que (what) será realizado em termos de melhorias, por que (why), onde (where), quando (when), por quem (who), como (how) e quanto custará (how much) a implementação dessas ações. Em paralelo, técnicas intuitivas podem ser utilizadas para explorar novas oportunidades e organizá-las de acordo com as personas identificadas anteriormente, tais como brainstorming, brainwriting, cardápio de ideias e matriz de posicionamento.

Por fim, a etapa de prototipação tem como objetivo facilitar a visualização inicial de como as ideias selecionadas poderão ser transformadas num novo modelo do processo (To $\mathrm{Be}$ ) para subsidiar a documentação final da análise ambidestra do processo de negócio. É importante frisar que a etapa de prototipação da análise caracteriza-se de forma diferente do Desenho de Processo, fase posterior a análise de processo prevista no ciclo BPM. Na fase de Desenho, por exemplo, a equipe responsável pela iniciativa de BPM utilizará a documentação gerada na análise para definir todas as regras do negócio, métricas e simulações mais robustas. Além disso, o modelo To Be deverá ser elaborado com mais rigor e detalhes a fim de representar como o processo deverá ser executado após a sua implementação.

Desse modo, a proposta da etapa de prototipação na análise é elaborar versões iniciais do processo de negócio para testar rápida e minimamente com os atores e 
clientes as oportunidades identificadas. Para isso, visões do processo poderão ser desenvolvidas por meio de storyboards, protótipos de papel/tela ou pela própria modelagem do processo para ser apresentadas aos stakeholders e coletar feedbacks. $\mathrm{O}$ resultado esperado é a documentação desses protótipos e dos feedbacks para auxiliar no desenho do novo modelo do processo de negócio.

\section{Avaliação do Método A2PN}

\subsection{Opinião de Especialistas}

Conforme descrito na Seção 3, o ciclo da Design Science Research contempla o desenvolvimento e avaliação de um artefato que tem a teoria como fundamentação e que possui um contexto de negócio para o qual ele deve ter utilidade prática. Após o desenvolvimento do artefato, foi realizada uma avaliação com o objetivo de verificar a utilidade e a facilidade de uso percebida sob o ponto de vista de especialistas da área de BPM. Descreve-se a seguir os perfis de cada um dos participantes:

Especialista 1: Atua com pesquisas em BPM desde 2008. Foi analista de negócios do SERPRO entre 2010 e 2012, trabalhando na estruturação do Escritório de Processos corporativo. Seu mestrado consistiu numa revisão sistemática da literatura, analisando o tópico "variabilidade de processos de negócio". Também já co-orientou trabalhos na área de BPM. Desde 2013, atua como gerente em um convênio de pesquisa entre uma Universidade e um órgão público, cuja principal atividade é a condução de projetos de melhoria de processos;

Especialista 2: Possui mais de 10 anos de experiência na área de TI. É consultor envolvido nas atividades de gestão, análise de sistemas, análise de requisitos, negociação e utilização dos conceitos, técnicas e boas práticas de BPM. Possui também experiência na utilização das práticas de BPM para definição do processo de negócio e uso de ferramentas de BPMS IBM/FileNet;

Especialista 3: Atua há mais de 20 anos no mercado de TIC tendo atuado como Gestora, Analista de Negócio e Arquiteta de Dados com forte experiência nas áreas judicial e hospitalar. Atualmente é Gerente do PMO num Tribunal de Justiça de Pernambuco. Além disso, atua como consultor num órgão público realizando atividades de modelagem, desenho, análise, implementação e monitoramento de processo. Também é Project Management Professional (PMP) e Certified Business Process Professional (CBPP) e Certified Scrum Master (CSM). E possui especializações em Gerência de Projetos, Automação e Melhoria de processos com abordagem de BPM, Qualidade de Software e Arquitetura de Dados e Negócio, Gestão de TIC, Lean/Kanban.

Especialista 4: Possui cerca de 23 anos de experiência profissional transitando nas áreas de tecnologia da informação, consultoria organizacional, gestão de processos em empresas públicas e privadas. Gerenciou projetos de BPM que envolveram todas as fases de BPM. Minha experiência envolveu também contratação de empresas para realização de projeto de BPM. Seu mestrado e doutorado foi na área de BPM. Possui relevante formação complementar em Gerenciamento de Projetos, Gestão de Processos e Consultoria organizacional, detendo certificações PMP e CBPP.

Especialista 5: É mestre em Ciência da Computação e atua na implantação de instrumentos (tecnológicos ou não) para competitividade e eficiência organizacional nas 
áreas de Gerência de Projetos, BPM, Qualidade e Auditoria Digital. Possui as certificações PMP e CBPP)

Especialista 6: É atualmente professor Universitário e leciona disciplinas com foco em BPM. Atua também como Consultor de Processos e vivenciou projetos BPM em diversas empresas. Nesses projetos, trabalhou desde a modelagem até automação dos processos com integração de serviços com web service e a camada SOA (ServiceOriented Architecture) possibilitando a integração dos processos de negócio da organização com os ERPs, Redes Sociais, E-commerce, etc.

Especialista 7: Atuou como consultor e gerente de equipe de analistas de processos em diversas empresas por meio de projetos de melhoria e automação de processos (BPM e BPMS) há cerca de nove anos. Seu mestrado é na área de BPM e considera sua experiência alta em projetos de BPM.

Como o artefato proposto é para ser aplicado por analistas de processos e organizações que querem analisar e melhorar seus processos de negócio, percebe-se que os especialistas convidados a participarem desta avaliação têm um perfil mais voltado para a área de Negócio e/ou Tecnologia da Informação com conhecimentos sólidos em BPM. Apenas um deles relatou que já participou de um projeto envolvendo Design Thinking, mas disse que sua experiência nesse assunto é baixa. Os demais apenas leram sobre o assunto ou nunca tiveram contato. Esse perfil foi escolhido pelo fato de ser parecido com o que será encontrado nas organizações que irão aplicar o método A2PN.

A avaliação consistiu em coletar feedbacks dos especialistas de acordo com sua imaginação e análise crítica do artefato proposto. Para isso, foi enviado um e-mail para todos eles em que explicava o contexto da pesquisa, o tempo disponível para avaliação, um link para o website em que estava o artefato e um link para o questionário de avaliação em que contemplou a utilidade e facilidade de uso percebida. Após a análise crítica do artefato proposto, os especialistas responderam ao questionário semiestruturado. Ele foi dividido em três categorias: facilidade de entendimento percebida; utilidade percebida; sugestões e críticas. Ao todo, ele continha oito questões abertas e cinco questões fechadas. As questões fechadas eram escritas em formato de assertivas e suas respostas variavam de Discordo Totalmente a Concordo Totalmente conforme a escala Likert de cinco pontos (Brown, 2000). Apenas as questões fechadas eram obrigatórias. A seguir, descreve-se os resultados dessa avaliação por questão.

\subsubsection{Facilidade de Entendimento Percebida}

A primeira questão refletia se o especialista achou fácil entender as fases, fluxo de atividades e tarefas propostas no método de análise ambidestra de processo de negócio. Como pode-se perceber na Figura 10, quatro especialistas afirmaram que concordam totalmente e três marcaram como concordam com a assertiva da primeira questão. 


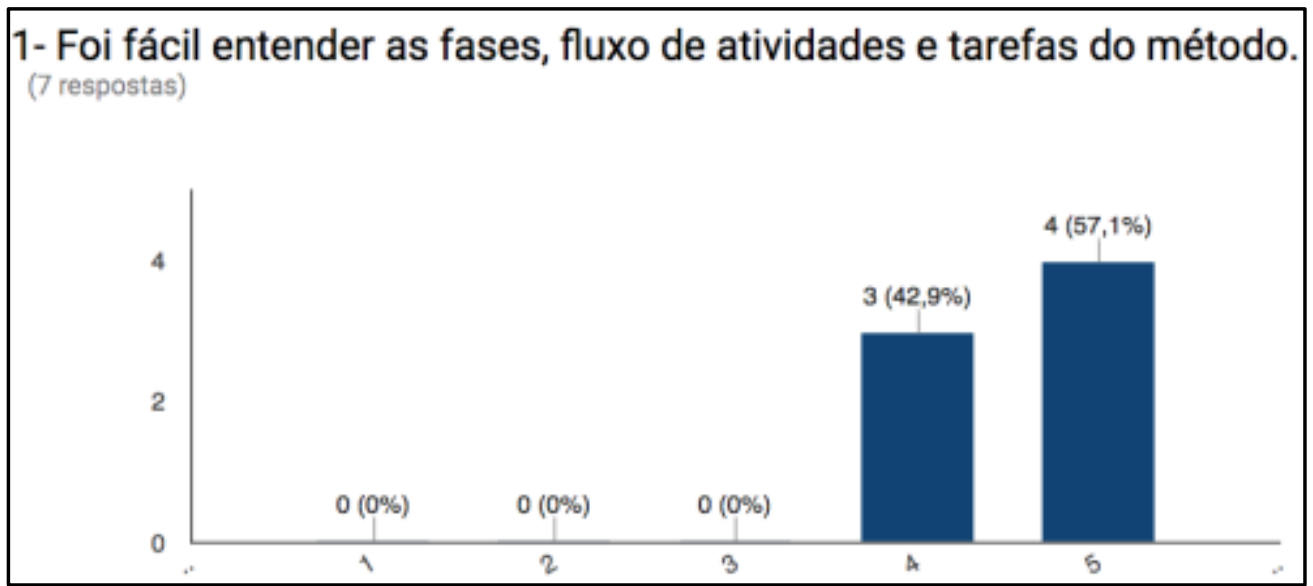

Figura 10. Primeira Questão

A segunda questão foi aberta. Nela, os especialistas foram questionados se tinham sugestões para facilitar o entendimento das fases, atividades e tarefas do método. Descreve-se a seguir as principais recomendações dos especialistas:

- "Unir das duas últimas tarefas da atividade 2 da etapa imersão. Colocar um termo mais abrangente, algo como Planejar coleta de dados";

- "Elaborar um glossário para explicar termos que não são autoexplicativos ('alinhamento parcial do entendimento')";

- "Aumentar o tamanho da caixa da atividade 3 da etapa de imersão pra dá uma ideia de que tudo abaixo pertence a ela";

- “Alterar o nome 'protótipo de processo' para versão inicial do modelo to-be para não confundir o usuário com mais um jargão";

- "Acho que as atividades 1 e 2 da fase 3 podem ser reunidas numa só, ou ter seus títulos alterados. Se for uma só, eu colocaria como "refinar documentação", que seria a revisão e a organização (geração de uma nova versão)";

- "Incluiria uma divulgação desse resultado de alguma forma para os envolvidos. Nem que fosse num site ou envio por e-mail";

A terceira questão foi uma assertiva sobre a clareza no entendimento de como utilizar as técnicas analíticas e intuitivas sugeridas no método. Como percebe-se na Figura 11, uma pessoa não concorda, uma ficou indecisa, quatro concordam e uma concorda totalmente que ficou claro como utilizar as técnicas. 


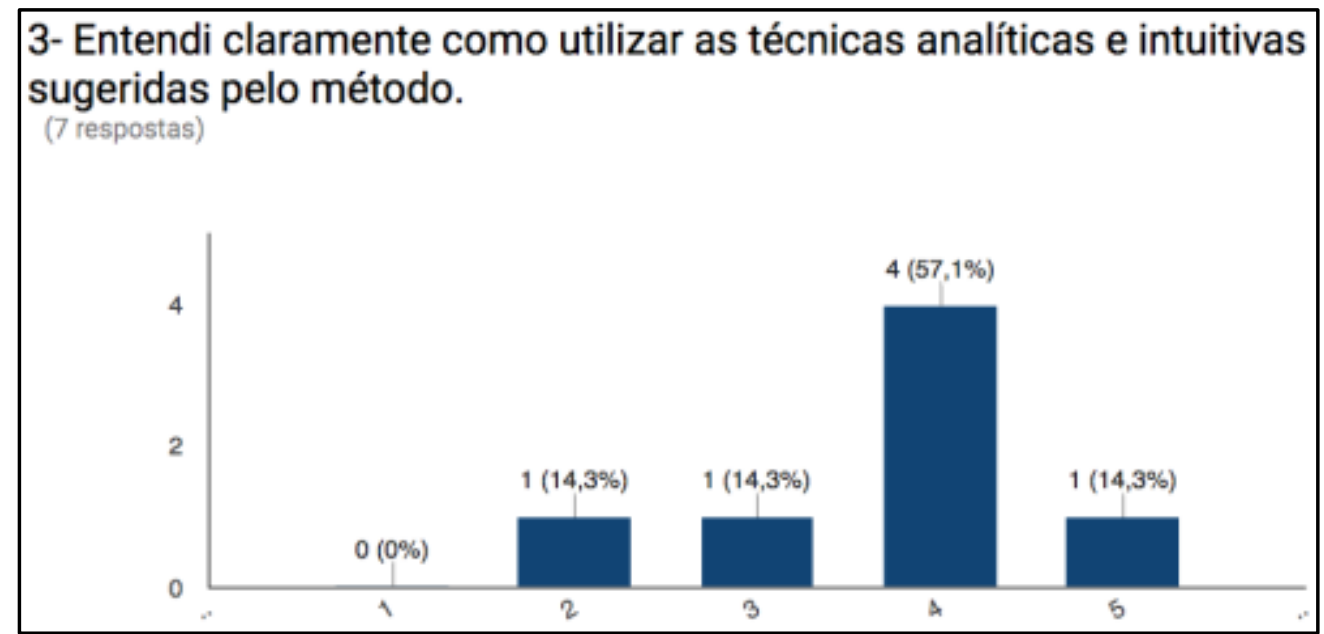

Figura 11. Terceira Questão

$\mathrm{Na}$ quarta questão, foi questionado como a descrição das técnicas poderia ser melhorada para facilitar o entendimento das mesmas. São listadas a seguir as sugestões fornecidas:

- "Estou achando o COMO não tão didático. Não caberia enumerar os passos? Quem quer acessar isso, quer aprender. Para uma primeira versão, como um todo, o trabalho está muito bom.

- "Poderia mesclar o COMO com passos e dicas. Os passos serem enumerados e formais. As dicas serem em bullets e menos formais";

- "Pode melhorar a imagem da técnica CRITÉRIOS NORTEADORES. As imagens devem trazer a ideia do resultado";

- "Deixar mais claro quais seriam os participantes principais/ obrigatórios e os desejáveis".

A quinta questão perguntou aos especialistas se eles têm sugestões de melhoria na organização de layout do site levando em consideração as cores, fontes, imagens, disposição dos textos, arquivos, etc. Todos os especialistas que responderam esta questão elogiaram o layout e organização do site. As duas únicas recomendações foram melhorar o apelo visual da página inicial e incluir informações sobre a pesquisa e o pesquisador.

\subsubsection{Utilidade Percebida}

A sexta questão que retrata se o especialista considera as fases, atividades e tarefas definidas como adequadas para realizar uma análise ambidestra de processo de negócio. Percebe-se na Figura 12 que um ficou indeciso, cinco concordam e um concorda totalmente com a assertiva. 


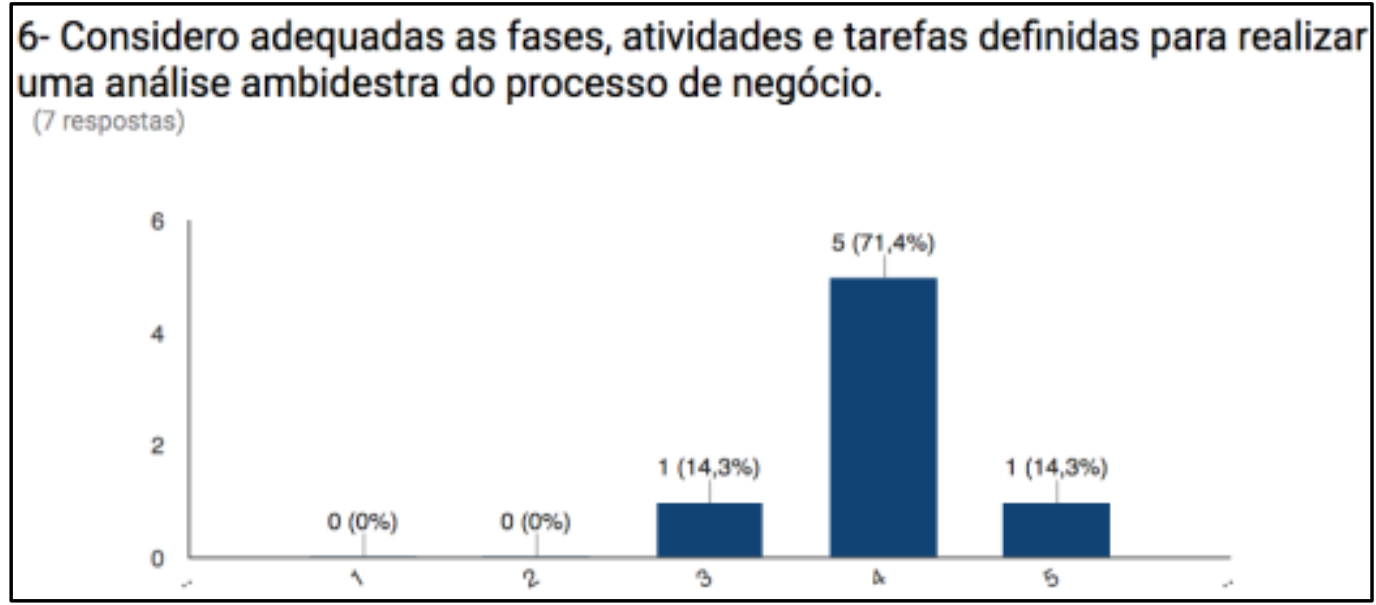

Figura 12. Sexta Questão

A sétima questão perguntou se os especialistas tinham sugestões para incrementar ou alterar as fases, atividades e tarefas para tornar o método com mais utilidade para a análise ambidestra do processo de negócio. Apenas sugeriu-se deixar mais claro no método quando usar ou dispensar determinada atividade, tarefa e/ou técnica.

A oitava questão pergunta se os especialistas consideram as técnicas analíticas e intuitivas adequadas para realizar melhorias incrementais e radicais no processo de negócio. De acordo com a Figura 13, um ficou indeciso, cinco concordam e um concorda totalmente com a assertiva.

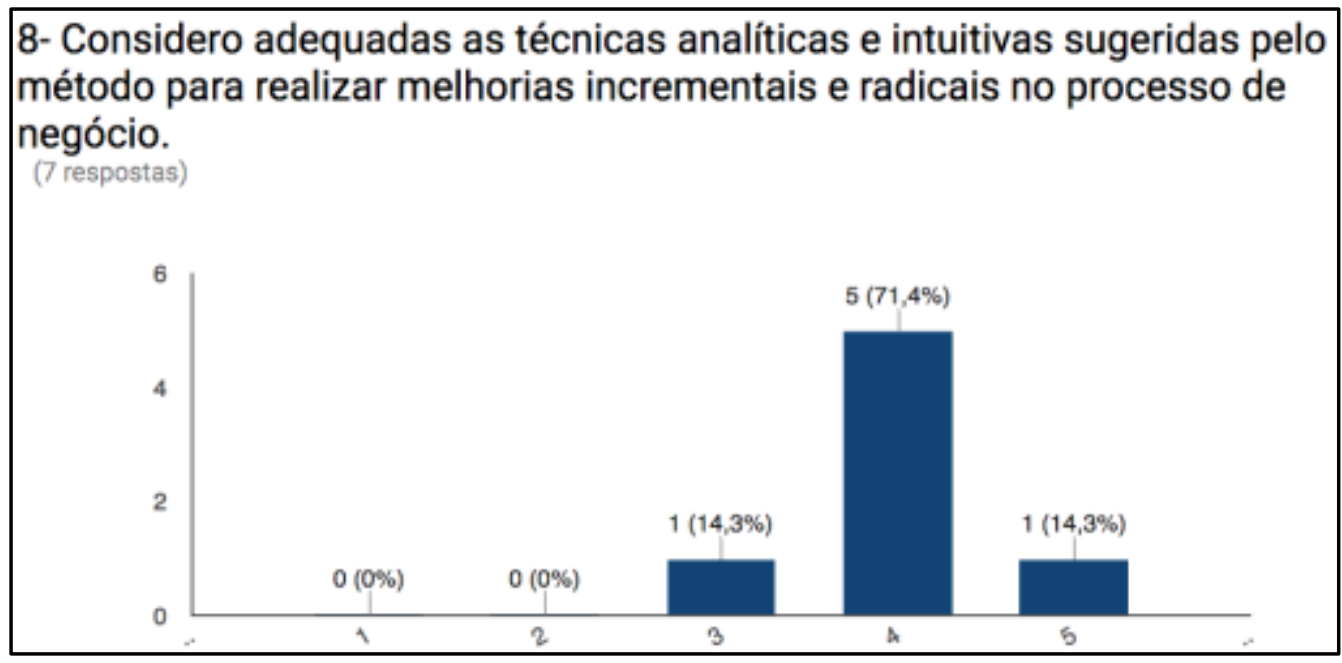

Figura 13. Oitava Questão

A nona questão pediu sugestões aos especialistas sobre a inclusão ou exclusão de alguma técnica. Não foi dada nenhuma sugestão para essa questão.

Como forma de representar melhor a utilização do método, foi elaborada uma documentação exemplo de análise ambidestra do processo de atendimento de uma pizzaria fictícia. Nessa documentação, os usuários podem observar os resultados das aplicações das técnicas presentes no método proposto. Diante disso, a questão 10 perguntou se o exemplo da pizzaria ajudou a aprender mais sobre a utilização e os 
resultados das técnicas. Como resultado visto na Figura 14, uma não concorda, dois ficaram indecisos e quatro concordaram totalmente com a assertiva dessa questão.

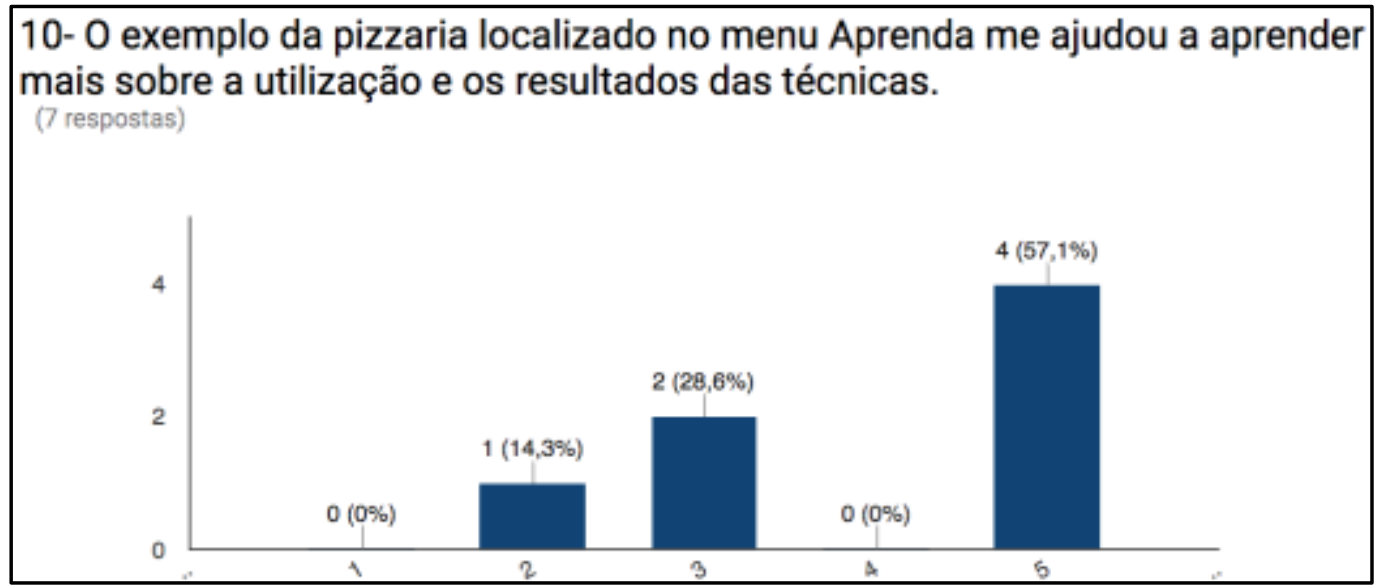

Figura 14. Décima Questão

A questão 11 perguntou aos especialistas se tinham sugestões para melhorar o exemplo disponibilizado. Duas sugestões foram para deixar o exemplo mais simples, pois acharam extenso.

\subsubsection{Experiência de Uso e Críticas}

Como forma de entender a percepção dos especialistas quanto a leitura e análise crítica do método proposto, a questão 12 perguntou como foi a sua experiência de uma forma geral. Cinco especialistas relataram suas experiências:

- "Ainda não utilizei na prática, mas acredito que seja uma experiência rica pelo uso de técnicas de criatividade. Só ao aplicar é que podemos verificar de fato a relevância e possiveis demandas de ajuste";

- "Eu concordo que é interessante, certamente colocando ele a prova em um projeto real, acredito que os resultados obtidos seriam bem interessantes";

- "Achei bastante interessante, porém pareceu um pouco "pesado" se considerado em todas as etapas/técnicas";

- "Achei interessante e curioso, pois percebi a junção de várias boas práticas dentro do método";

- "Considero a experiência muito boa. A utilização das técnicas intuitivas estimula a gente pensar de outra forma além do que estamos acostumados".

Por fim, a questão 12 perguntou como o método poderia ser melhorado, o que sentiu falta e gostaria que fosse implementado. Foram sugeridos:

- "Elaborar um vídeo explicativo sobre o método de uma maneira geral";

- "Incluir informações de um estudo de caso real";

- "Relatos de experiências quanto a dificuldades e facilidades encontradas no uso do método";

- "Um modelo de avaliação com indicadores estabelecidos para monitorar a aderência da aplicação do método". 


\subsection{Entrevistas com Analistas de Processos}

Após a análise das respostas dos especialistas e refinamento do método A2PN, ele foi submetido a uma aplicação numa organização que possui 4 anos de experiência com inciativas de BPM. Essa aplicação foi realizada por três analistas de processo que atuam numa organização que tem como função realizar o controle externo. A ela compete examinar a legalidade, legitimidade, economicidade e razoabilidade de qualquer ato administrativo de que resulte receita ou despesa. Pelo fato do método A2PN ser mais adequado para processos que começam e terminam no cliente da organização, conforme descrito na Seção 4, o processo escolhido para realizar a análise ambidestra foi o de denúncia.

O processo de denúncia possui as seguintes fases: formalização, instrução, julgamento e publicação. Inicialmente, o cidadão entrega uma petição ao setor de protocolo. Pode ser uma pessoa física ou jurídica. Em seguida, os requisitos de admissibilidade são verificados e o setor de protocolo a encaminha ao conselheiro para autorizar a formalização do processo. Ao ser formalizado, o processo vai para auditoria.

$\mathrm{O}$ auditor redige um relatório com a confirmação ou rejeição dos fatos alegados pelo denunciante. Concluído o caso para julgamento, o gabinete do conselheiro prevê a preparação da votação e apresenta o caso a ser julgamento pelo colegiado com base no relatório de auditoria. $\mathrm{Na}$ sequência da decisão, o processo prossegue para a implementação das resoluções incluídas na decisão e o seu resultado é publicado no diário oficial do Estado.

Conforme descrito na Seção 4, a aplicação do método A2PN tem como entrada o modelo de processo As-Is. Para modelar o estado atual do processo de denúncia, os três analistas de processo entrevistaram três funcionários responsáveis pela fase de formalização, seis funcionários da instrução, três funcionários envolvidos no julgamento e dois na publicação. No total, foram realizadas 14 entrevistas para criar o modelo As-Is.

Com a entrada do modelo de As-Is do processo de denúncia, foram realizadas as atividades da fase de planejamento do método A2PN. Inicialmente, a equipe coletou informações relacionadas ao processo de denúncia por meio da técnica analítica: pesquisa documental. Entre os documentos pesquisados estão a Lei Orgânica $n^{\circ} 12.600$, de 2004, e a Resolução no 008/2006, referente ao processo de denúncia. Para estabelecer o escopo da análise, os analistas convidaram três atores responsáveis pelo processo de denúncia que tinham funções de gestores de suas áreas funcionais. A equipe apresentou o modelo As-Is para as partes interessadas e discutiram problemas e oportunidades com a técnica intuitiva brainstorming. Após a reunião, duas Oportunidades de Melhoria $(\mathrm{OM})$ a serem exploradas durante a análise:

- OM1: existem duas modalidades processuais que fazem as mesmas atividades e são tratadas de forma diferente (auditoria especial e denúncia). Isso causa retrabalho e desperdício de tempo;

- OM2: os denunciantes escrevem informações referente a denúncia de formas muito diferentes. Isso causa confusão e atrasos no setor de formalização de denúncia.

Com essas informações geradas, foi elaborado a primeira versão do plano de análise contendo as principais atividades a serem realizadas juntamente com um 
cronograma. Em seguida, iniciou-se a fase de Realização do método A2PN composta pelas etapas de Imersão, Definição, Ideação e Prototipação. Na etapa de Imersão, foi realizada uma revisão do processo de negócio entre a equipe de análise (atividade 1) e uma houve uma preparação de como seria o aprendizado junto aos atores e clientes do processo de negócio (atividade 2).

A atividade 3 da etapa de Imersão que contempla aprender mais sobre o modelo As-Is do processo foi realizada com um cliente e dois funcionários do setor de protocolo, os quais são responsáveis pelo recebimento da petição de denúncia junto ao cliente. Por meio da técnica Entrevista com Empatia, foi identificado que o cliente não recebe previsão de quando os fatos serão investigados. Após entrar com a petição de denúncia, ele recebe um número de protocolo para acompanhar sua evolução pelo site da organização a partir da sua formalização como denúncia. No entanto, do período em que ele entra com a petição até sua formalização, o denunciante não recebe informações sobre o andamento de sua petição. Dessa forma, além dos dois problemas identificados na fase de planejamento, investigou-se também a Oportunidade de Melhoria (OM3) referente ao denunciante ficar sem resposta quando o processo não é formalizado. Percebeu-se que isso causa frustração na expectativa dele e falta de visão da organização sobre a satisfação do cliente ao longo do processo.

Após as entrevistas com empatia, iniciou-se a etapa de Definição. A atividade 4, que contemplou o compartilhamento do aprendizado, foi realizada com a participação do gerente da iniciativa e os dois analistas de processos por meio do relato das entrevistas e preenchimento do mapa da empatia. Em seguida, as atividades 5 e 6 foram realizadas para categorizar esses aprendizados e estruturar as oportunidades identificadas. Foram utilizadas a técnica analítica Diagrama de Ishikawa e as técnicas intuitivas Cartões de Insights, Diagrama de Afinidades e Jornada do Usuário. Além das três citadas anteriormente, foram categorizadas mais três possíveis oportunidades de melhoria no processo. Tais como: (OM4) a descrição da denúncia é mal elaborada pelo cliente; (OM5) não há uma definição padrão para os conselheiros formalizarem as petições como denúncia; e (OM6) as informações contidas no site referente aos despachos de cada setor não são de fácil entendimento para o cliente porque contêm muitas siglas e jargões utilizados internamente pela organização.

Diante das seis oportunidades de melhoria identificadas pelos analistas de processo, foram priorizados quatro para serem trabalhados na etapa de Ideação. Para cada ponto de melhoria, foram geradas ideias (atividade 7) e depois refinadas (atividade 8) por meio da técnica analítica $5 \mathrm{~W} 2 \mathrm{H}$ e da técnica intuitiva Brainstorming. Após as discussões e documentação das ideias geradas, foram prototipadas possíveis soluções para cada OM conforme as atividades 9 e 10 do método A2PN. Para a OM1, investigou-se como outra organização trata modalidades de processos diferentes como uma única forma de processo e percebeu-se que é viável implementar esta solução. Sobre a OM2, foi elaborada uma nova versão da folha informativa com a intenção de padronizar todos os dados referentes a denúncia.

Com relação a OM3, a ideia escolhida para prototipação foi melhorar a rastreabilidade do processo por meio de notificações ao denunciante toda vez que sua petição de denúncia mudar de status dentro da organização. Essa notificação poderá ser recebida por SMS e/ou por e-mail, a escolha do cliente. Para contemplar a OM4, 
decidiu-se disponibilizar um guia demonstrativo no site da organização sobre como preencher a petição de denúncia para evitar confusões e divergências.

Para que as ideias referentes a OM5 fossem posteriormente implementadas, a presença e concordância dos conselheiros nesta etapa seria fundamental. No entanto, no período desta avaliação do método, não foi possível conciliar a agenda deles para executar as atividades 7 e 8. Para contemplar a OM6, foram gerados exemplos de despachos para que cada setor possa explicar detalhadamente o que aconteceu e quais os próximos passos.

Por fim, os analistas de processos refinaram toda a documentação gerada nessa iniciativa e foi realizada uma reunião com os stakeholders com a intenção de apresentar os resultados obtidos. Com a conclusão da fase de Encerramento, a aplicação do método A2PN foi concluída e iniciou-se a discussão sobre o desenho To Be do processo de denúncia.

Após a aplicação do método A2PN, foram realizadas entrevistas semiestruturadas, conforme roteiro apresentado na Tabela 6 , com cada analista de processo para avaliar a utilidade percebida, facilidade de entendimento, aplicabilidade e limitações do método A2PN. Ressalta-se que esse roteiro foi adaptado de (BUKHSH, 2015).

Tabela 6. Roteiro da Entrevista Semiestruturada com os Analistas de Processo

\begin{tabular}{|l|l|}
\hline \multicolumn{1}{|c|}{ Critério } & \multicolumn{1}{c|}{ Perguntas } \\
\hline $\begin{array}{l}\text { Utilidade } \\
\text { Percebida }\end{array}$ & $\begin{array}{l}\text { Do ponto de vista prático, você acredita que utilizar técnicas analíticas e } \\
\text { intuitivas foi significante para encontrar e analisar problemas e } \\
\text { oportunidades? Sugere alguma modificação? }\end{array}$ \\
\hline $\begin{array}{l}\text { Facilidade de } \\
\text { Entendimento }\end{array}$ & $\begin{array}{l}\text { Como você avalia a facilidade de entendimento no método A2PN? Suas } \\
\text { fases, atividades, técnicas. Você tem alguma sugestão de mudança? }\end{array}$ \\
\hline Aplicabilidade & $\begin{array}{l}\text { Como você avalia o método A2PN quanto a sua aplicabilidade? Você acha } \\
\text { que consegue aplicá-lo sem ajuda de um especialista no método? Pode nos } \\
\text { citar alguns problemas encontrados? }\end{array}$ \\
\hline $\begin{array}{l}\text { Limitações do } \\
\text { A2PN }\end{array}$ & $\begin{array}{l}\text { De acordo com sua experiência na utilização do método, quais foram suas } \\
\text { dificuldades ao longo da análise ambidestra do processo? Sentiu falta de } \\
\text { alguma coisa? }\end{array}$ \\
\hline
\end{tabular}

\subsubsection{Utilidade Percebida}

Foram realizadas duas perguntas referente ao critério de utilidade percebida. Todos os três analistas julgaram que a utilização das técnicas analíticas e intuitivas de forma conjunta foi significante para identificar e analisar as oportunidades no processo de denúncia. Um deles relatou: "Achei que organizou melhor os dados que foram coletados. Por exemplo, a técnica de personas deixou claro as características dos perfis. Talvez se só fosse utilizar as analíticas ficaria um pouco incompleto e dificultaria a visualização de algumas oportunidades de melhoria".

Outro analista de processo ressaltou que as técnicas intuitivas engajaram melhor os participantes ao longo da análise. Ele afirmou que: "Quando a gente estava fazendo a entrevista com empatia, ficou mais fácil para os participantes entenderem porque fizemos as perguntas baseadas nas reuniões. Mostramos o diagrama da espinha de peixe, jornada do usuário e as personas". O que chamou atenção no terceiro analista foi o fato das técnicas analíticas auxiliarem na identificação dos problemas internos e as 
intuitivas no estabelecimento dos perfis dos clientes e identificação das suas dores e expectativas.

\subsubsection{Facilidade de Entendimento}

Todos os analistas também avaliaram positivamente este critério no método e apresentaram sugestões de melhoria. Um deles comentou: "Achei que o método está bem organizado em termos de etapas, atividades... Achei que o exemplo da pizzaria foi bem interessante". O outro afirmou: "Tudo que tinha no site, eu achei fácil de entender.... Do que eu já sabia, estava bem claro. E o que eu não sabia, não tive dificuldade em aprender...". Por fim, o terceiro analista disse que "A descrição das atividades, técnicas estava de fácil entendimento... A figura representando as etapas de Design Thinking ficou muito bom também".

Como sugestões, um analista disse que "Poderia só deixar claro que alguns nomes são botões. Em alguns momentos, não percebi que eram botões". E um outro afirmou que "... O template jornada do usuário não está fácil de entender como deve ser seu preenchimento".

\subsubsection{Aplicabilidade}

Um analista afirmou que num primeiro momento necessitaria da ajuda de um especialista no método para que uma organização possa aplicá-lo na análise de um processo de negócio. Essa ajuda seria principalmente importante no momento de escolher qual técnica é melhor para cada situação. Porém, os outros dois ressaltaram que é possível sua aplicação sem a ajuda de um especialista: "o método é bem direto e com um caminho fácil de seguir...". Além disso, foi citado que "Como a organização é bastante conservadora, acho que técnicas muito criativas fogem muito do costume dos usuários. Tivemos um pouco de dificuldades, mas conseguimos gerar resultados".

\subsubsection{Limitações do A2PN}

Além de algumas limitações já citadas anteriormente, os analistas afirmaram que alguns resultados esperados não estão claros de como devem ser representados ou descritos num documento referente a análise do processo. Um analista comentou que a falta de experiência nas técnicas intuitivas acarretou num período maior de aprendizado para começar de fato a análise do processo. Outro ressaltou que deveria estar claro no método que ele pode ser utilizado em conjunto com uma metodologia BPM já existente na organização.

\section{Considerações Finais e Trabalhos Futuros}

Este artigo apresentou como principal resultado da pesquisa o método A2PN que sistematiza a fase de análise de processos de negócio e permite que melhorias incrementais e/ou inovações de processo sejam propostas. Do ponto de vista científico, a contribuição desta pesquisa está relacionada a apresentação dos modelos conceituais identificados na literatura, a discussão, relação entre os princípios da Ambidestria Organizacional e práticas de Design Thinking na fase de análise da Gestão de Processos de Negócio. Por sua vez, a contribuição prática refere-se ao desenvolvimento do método de Análise Ambidestra de Processo de Negócio que tem como proposta permitir as organizações manterem sua preocupação em melhorar continuamente e estarem atentas 
às oportunidades externas para inovarem seus processos de negócio por meio de uma análise que leva em consideração os pensamentos analítico e intuitivo.

Com relação a (QP1) Quais são modelos existentes que exploram as capacidades ambidestras e inovação de processos de negócio? - foi constatado na pesquisa bibliográfica que a maioria das pesquisas ainda aborda práticas e técnicas analíticas para melhorar processos de negócio. No entanto, observou-se um crescente interesse e discussão sobre a necessidade de utilizar práticas e técnicas intuitivas de forma equilibrada com as analíticas nas iniciativas de BPM. Diante disso, identificou-se cinco modelos que caracterizam capacidades e técnicas para alcançar a ambidestria organizacional e possibilitar a melhoria e/ou inovação de processos de negócio.

Referente a (QP2) Como sistematizar a análise ambidestra de processos de negócio? - foi construído, por meio da Design Science Research, um método para apoiar os analistas de processos na realização de práticas que envolvem o pensamento analítico e intuitivo. Dessa forma, além da reflexão sobre os problemas existentes que as tradicionais técnicas de análise de processo investigam, o método para análise ambidestra de processo de negócio tem como objetivo permitir que os analistas explorem oportunidades além da fronteira organizacional por meio de técnicas divergentes e convergentes.

Por se basear no método DSR, foi realizada também uma avaliação com especialistas da área de BPM sobre a utilidade e facilidade de uso percebida do método proposto e uma aplicação do método A2PN numa organização real. Conforme os resultados obtidos e relatados na Seção 6, pode-se afirmar que o método foi considerado de fácil utilização e adequado para fomentar o equilíbrio entre os pensamentos analítico e intuitivo. Um ponto interessante evidenciado na aplicação do método na organização refere-se ao fato de que mesmo conservadora e acostumada com técnicas analíticas, foi possível aplicar técnicas criativas, identificar oportunidades fora de sua fronteira e gerar resultados específicos para seus clientes. Além disso, tanto os especialistas quanto os analistas de processo forneceram várias sugestões de melhorias no que se refere a organização e alteração das atividades, mudanças na forma de apresentação das técnicas e criação de um glossário para alinhar o entendimento entre os envolvidos.

Apesar de priorizar a qualidade das informações nesse momento, considera-se como principal limitação a baixa quantidade de especialistas e analistas de processo participantes da avaliação. Diante disso, além de não ser possível afirmar que o método proposto cumpre com seus objetivos e contém todos os elementos adequados, ressaltase que os resultados possuem uma baixa generalização.

Apesar de uma pesquisa científica alcançar os objetivos que se propôs em seu planejamento, sempre haverá a possibilidade do autor dar continuidade a pesquisa e sugerir oportunidades que visem complementar os resultados encontrados. Nesse aspecto, como trabalho futuro propõe-se realizar um quasi-experimento na análise de um processo de negócio com a intenção de comparar os resultados gerados com e sem a utilização do método proposto neste trabalho.

\section{Referências}

ABPMP (2013) BPM CBOK - Guide to the Business Process Management Common Body of Knowledge, Versão 3. 
Ang, J.; Pee, L.; Iijima, J. (2013) Investigating the effects of business process orientation on organizational innovation performance. In Information \& Management, v. 50, n. 8, p. 11.

Bauer, M.; Leker, J. (2013) Exploration and exploitation in product and process innovation in the chemical industry. In R\&D Management, v. 43, n. 3, p. 196-212.

Brown, J. D. (2000) What issues affect Likert-scale questionnaire formats? In: JALT Testing \& Evaluation SIG Newsletter, Manoa, v. 4, n. 1, p. 18-21,.

Brown, T. (2009) Change by design: how design thinking transforms organizations and inspires innovation. New York: Harper Business.

Brown, T. (2008) Design thinking. In Harvard Business Review, v. 86, n. 6, p. 84-95.

Brown, T.; Wyatt, J. (2010 ) "Design Thinking for Social Innovation". Open Knowledge Repository, July. Disponivel em: $<$ https://openknowledge.worldbank.com/handle/10986/6068 $>$. Acesso em: jul. 2014.

Bukhsh, Z. (2015) "BPMN Plus: A Modelling Language for Unstructured Business Processes". Thesis. University of Twente. 144 pp.

Chasanidou, D.; Gasparini, A.; Lee, E. (2014) Design Thinking Methods and Tools for Innovation in Multidisciplinary Teams. In Workshop Innovation in HCI. Helsinki, Finland: NordiCHI'14. 2014. p. 27-30.

Chen, E.; Katila, R. (2008) "Rival interpretations of balancing exploration and exploitation: Simultaneous or sequential?" In: SHANE, S. Handbook of Technology and Innovation Management. NY: Wiley, v. 1.

Creswell, J.W. (2009), Research Design: Qualitative, Quantitative, and Mixed Methods Approaches, Sage, Thousand Oaks, CA.

Davis, F.; Bagozzi, R.; Warshaw, P. (1989) User Acceptance of Computer Technology: A Comparison of Two Theoretical Models. In Journal Management Science, v. 35, n. 8, p. 982-1003, Aug.

Duncan, R. B. (1976) "The ambidextrous organization: Designing dual structures for innovation". In: KILMANN, H.; PONDY, L. R.; SLEVIN, D. The management of organization design: Strategies and implementation. New York: North Holland. p. 167-188.

Easterbrook, S. et al. (2008) "Selecting Empirical Methods for Software Engineering Research". In: SHULL, F.; SINGER, J.; SJOBERG, D. Guide to Advanced Empirical Software Engineering. London: Springer. p. 285-311.

Gibson, C.; Birkinshaw, J. (2004) The antecedents, consequences, and mediating role of organizational ambidexterity. In Academy of Management Journal, v. 47, p. 209-226.

Grover, V.; Karkus, M. (2008) Business Process Transformation. Armonk, New York: M.E. Sharpe, v. 9.

Harmon, P.; Wolf, C. (2014) The State of Business Process Management. A BPTrends Report.

Henderson, R. M. and K. B. Clark (1990). Architec- tural innovation: The reconfiguration of existing product technologies and the failure of established firms. In Administrative Science Quarterly, 35, pp. 9-30. 
Hevner, A., March, S., Park, J. and Ram, S. (2004) Design science in information systems research. In MIS Quarterly, vol. 28, no. 1, pp. 75-106.

IIBA (2009) "A Guide to the Business Analysis Body of Knowledge (BABOK Guide)". Toronto: International Institute of Business Analysis, v. 2.

Jurisch, M. et al. (2014) Which capabilities matter for successful business process change?. In Business Process Management Journal, v. 20, n. 1, p. 47-67.

Kohlborn, T., Mueller, O., Poeppelbuss, J. and Roeglinger, M. (2014) Interview with Michael Rosemann on Ambidextrous Business Process Management. In Business Process Management Journal, vol. 20, no. 4, pp. 634-638.

Kotler, P. and Armstrong, G. (2009) "Principles of Marketing", 13 ed., London: Prentice Hall.

Lin, H.-E. et al. (2013) Managing the Exploitation/Exploration Paradox: The Role of a Learning Capability and Innovation Ambidexterity. In Journal of Product Innovation Management, 30(2), pp.262-278.

Ling, H.; Zhao, F.; Wang, Y. (2009 ) "Impact of Synergy Between IT and Business Process on Organizational Performance: A Perspective of Ambidexterity Theory". Pacific Asia Conference on Information Systems (PACIS). Hyderabad, India: AISeL. 2009. p. Paper 116.

Luebbe, A.; Weske, M. (2011) "Bringing Design Thinking to Business Process Modeling". In: MEINEL, C.; LEIFER, L.; PLATTNER, H. Design Thinking: Understand - Improve - Apply. Berlin: Springer-Verlag. p. 181-195.

Malinova, M.; Brina, H.; Mendling, J. (2014 ) "A framework for assessing bpm success". Twenty Second European Conference on Information Systems. Tel Aviv. p. 1-15.

March, J. (1991) Exploration and exploitation in organizational learning. In Organization Science, v. 2, n. 1, p. 71-87.

Marshall, M. (1996) "Sampling for qualitative research". Family Pratice, v. 13, n. 6.

Martin, R. (2009) "The Design of Business: Why Design Thinking is the Next Competitive Advantage", 3rd edition, Boston: Harvard Business Review.

Morais, R. et al. An analysis of BPM lifecycles: from a literature review to a framework proposal. In Business Process Management Journal, v. 20, n. 3, p. 412-432, 2014.

Niehaves, B.; Henser, J. (2011) "Business Process Management beyond Boundaries? A Multiple Case Study Exploration of Obstacles to Collaborative BPM". 44th Hawaii International Conference on System Sciences. Kanuai: IEEE. p. 1-13.

O'Reilly, C.; Tushman, M. (2008) Ambidexterity as a dynamic capability: Resolving the innovator's dilemma. In Research in Organizational Behavior, v. 28, p. 185-206.

O'Reilly, C.; Tushman, M. (2013) Organizational Ambidexterity: Past, Present, and Future. In Academy of Management Perspectives, v. 27, n. 4, p. 324-338.

Patton, Q. (2002) “Qualitative Research \& Evaluation Methods”. 3. ed. California: Sage Publications. 
PMI. (2013). A Guide to the Project Management Body of Knowledge $\left(\mathrm{PMBOK}^{\circledR}\right.$ Guide) - Fifth Edition. Project Management Institute (PMI).

Recker, J.; Rosemann, M. (2014) "Being Innovative Without Being Creative". Queensland University of Technology. Brisbane, Australia.

Richardson, C., Leaver, S., Cullen, A., Keenan, J. (2013) 'Design For Disruption: Take An Outside-In Approach To BPM”. Cambridge: Forrester Research.

Rosemann, M. (2014) "Proposals for future BPM research directions", 2nd Asia Pacific Business Process Management Conference, Brisbane, p. 1-15.

Rosemann, M. (2012) “The Three Drivers of Innovation”. IRM UK Newsletter, p. 1-6.

Rubin, R. and Rubin, I. (2011) "Qualitative interviewing: The art of hearing data". Sage.

Santos, H., Valença, G., Alvez, C. (2015) Strategies for Managing Critical Success Factors of BPM Initiatives in Brazilian Public Organizations: A Qualitative Empirical Study. In iSys - Revista Brasileira de Sistemas de Informação, Rio de Janeiro, vol. 8, No. 1, p. 42-64.

Schumpeter, J. A. (1942). Capitalism, Socialism, and Democracy. Harper, New York.

Tarafdar, M.; Gordon, S. (2007) Understanding the influence of information systems competencies on process innovation: A resource-based view. In The Journal of Strategic Information Systems, v. 16, n. 4, p. 353-392.

Trkman, P. (2010) The critical success factors of business process management. In International Journal of Information Management, vol. 30, no. 2, 125-134.

Tushman, M., O'Reilly, C. (1996) Ambidextrous organizations: Managing evolutionary and revolutionary Change. In California Management Review, v. 384, n. 8.

Vergidis, K., Tiwari, A. and Majeed, B. (2008) "Business Process Analysis and Optimization: Beyond Reengineering”, IEEE Transactions on Systems, Man, and Cybernetics, vol. 38, n. 1, pp. 69-82.

Voigt, Ortbach, Plattfaut, \& Niehaves (2013) IT Support for Business Process Innovation -- Architectural Choices and Design Challenges. 46th Hawaii International Conference on System Sciences. Maui: IEEE.

Wieringa, R. (2010) "Relevance and problem choice in design science". Global Perspectives on Design Science Research, p. 61-76.

Wieringa, R. (2014). "Design Science Methodology for Information Systems and Software Engineering". Springer-Verlag Berlin Heidelberg

Xie, R.; Ling, H.; Zhang, C. (2011) Effect of business process management on firm performance: An ambidexterity perspective. In International Conference on Business Management and Electronic Information, p. 341-345.

Yigit, M. (2013) "Organizational Ambidexterity: Balancing Exploitation and Exploration in Organizations”. School of Management. Karlskrona, Suécia. 